\title{
Review and Meta-Analysis of EVs: Embodied Emissions and Environmental Breakeven
}

\author{
Kevin Joseph Dillman 1,*(i), Áróra Árnadóttir ${ }^{2}$, Jukka Heinonen 2,3®, Michał Czepkiewicz ${ }^{2}$ (D) \\ and Brynhildur Davíðsdóttir 1 \\ 1 Department of Environment and Natural Resources, School of Engineering and Natural Sciences, \\ University of Iceland, 107 Reykjavík, Iceland; bdavids@hi.is \\ 2 Department of Civil and Environmental Engineering, School of Engineering and Natural Sciences, \\ University of Iceland, 107 Reykjavík, Iceland; ara32@hi.is (Á.Á.); heinonen@hi.is (J.H.); \\ michal.czepkiewicz@gmail.com (M.C.) \\ 3 Department of Built Environment, Aalto University, 00076 Aalto, Finland \\ * Correspondence: kjd2@hi.is
}

Received: 23 September 2020; Accepted: 10 November 2020; Published: 11 November 2020

\begin{abstract}
Electric vehicles (EVs) are often considered a potential solution to mitigate greenhouse gas (GHG) emissions originating from personal transport vehicles, but this has also been questioned due to their high production emissions. In this study, we performed an extensive literature review of existing EV life-cycle assessments (LCAs) and a meta-analysis of the studies in the review, extracting life-cycle GHG emission data combined with a standardized methodology for estimating GHG electrical grid intensities across the European Economic Area (EEA), which were used to estimate a set of environmental breakeven points for each EEA country. A Monte Carlo simulation was performed to provide sensitivity analysis. The results of the review suggest a need for greater methodological and data transparency within EV LCA research. The meta-analysis found a subset of countries across the EEA where there is a potential that EVs could lead to greater life-cycle GHG emissions than a comparable diesel counterpart. A policy discussion highlights how EV policies in countries with contrasting GHG electric grid intensities may not reflect the current techno-environmental reality. This paper emphasizes the importance for researchers to accurately depict life-cycle vehicle emissions and the need for EEA countries to enact policies corresponding to their respective contextual conditions to avoid potentially enacting policies that could lead to greater GHG emissions.
\end{abstract}

Keywords: electric vehicles; meta-analysis; environmental breakeven; e-mobility; life cycle analysis; EV LCA

\section{Introduction}

The transportation sector plays a significant role in the emission of greenhouse gases (GHGs), accounting for over $20 \%$ of energy-related greenhouse gas (GHG) emissions globally [1,2]. With the inclusion of "well-to-tank" (WTT) emissions associated with the production and distribution of the fuels needed to power these vehicles, this share would be even higher [3]. The Fifth Intergovernmental Panel on Climate Change (IPCC) assessment report estimates that transport emissions could increase faster than all other energy end-use sectors unless sustained mitigation policies are implemented [2]. The European Commission has acknowledged the need to create a framework to transition to low-emission mobility, as the EU relies on oil products for approximately $94 \%$ of its transport energy needs. The transportation fleet's electrification is a leading solution under consideration, and electric vehicles (EVs) are a crucial technology within this solution [1].

As policies are being put in place to decrease the GHG emissions associated with the transportation sector, the critical question should be how large the mitigation potential is when all emissions related 
to the transition to e-mobility are taken into account. This issue becomes prominent due to the high material and energy needed to produce and operate the vehicles and the high variation in the GHG intensities of energy grids worldwide.

Life-cycle assessment (LCA) provides a standardized methodology to answer this question [4]. LCA attempts to capture the life cycle and determine the environmental impacts of different processes within the product's life cycle. The life cycle of a vehicle (Figure 1) illustrates the key phases within a vehicle's life cycle, which can broadly be categorized into the vehicle's production, the vehicle's use phase, and the end of life (EOL) of the vehicle.

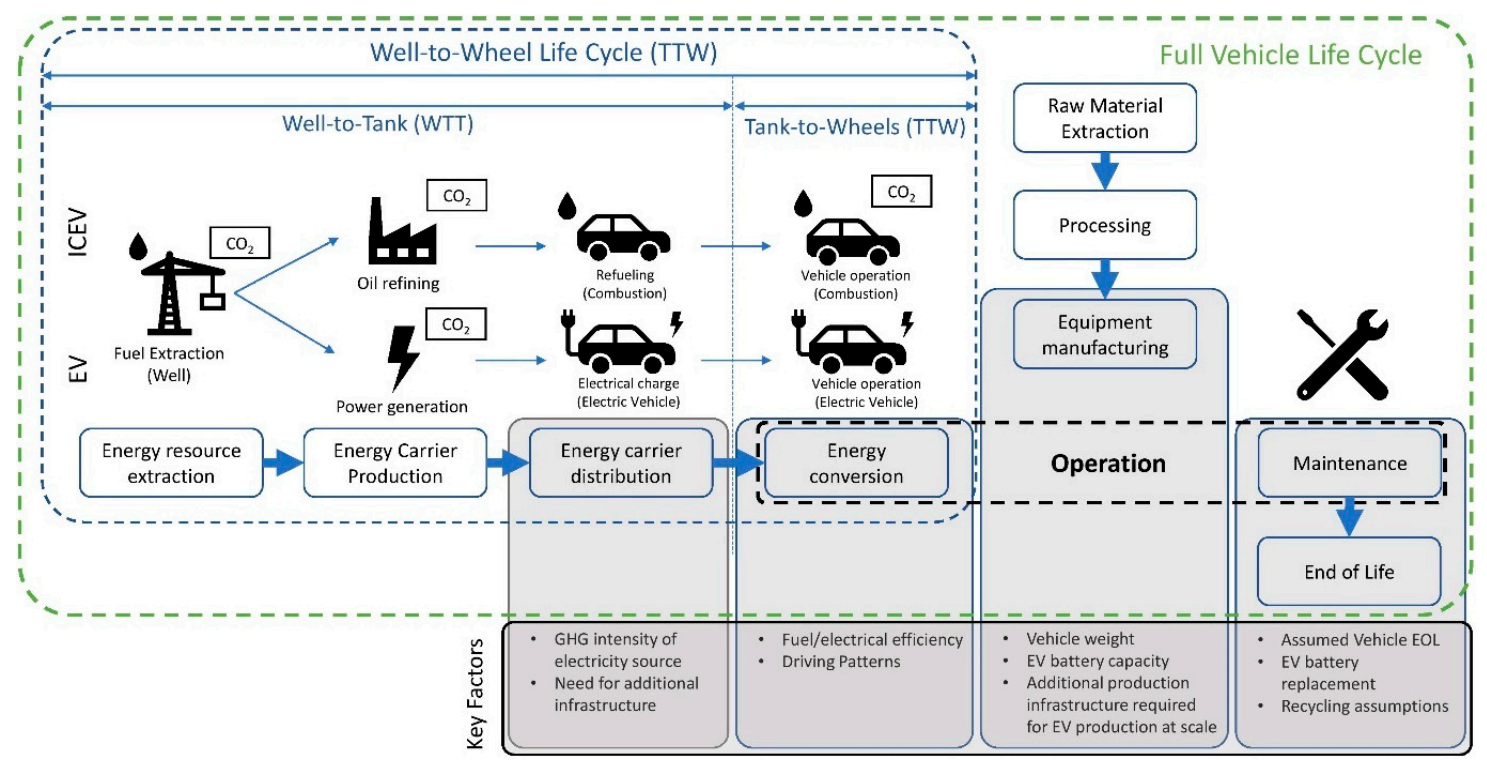

Figure 1. Illustration of a vehicle life cycle (adapted from [5,6]).

Unsurprisingly, LCA has been applied in numerous EV studies, and interest in the topic continues to grow as EV technology and market share develop. However, these studies' results vary, as is common when surveying a field of LCA studies for differing technologies, leaving the results of such studies and the suggested mitigation potential of EVs uncertain. Efforts can be made to synthesize this field of data for a more conclusive assessment. However, this can prove challenging due to inconsistencies in each study's scopes and methods [7].

Previous attempts to overcome this challenge in the form of literature reviews on LCAs of EVs have been performed, discussing sources of variability and shortcomings present within the literature [6,8,9]. The review of Hawkins et al. [8] emphasized the lack of data within different life-cycle phases. Nordelöf et al. [6] review was critical of the lacking temporal aspect within LCA studies, particularly concerning the rapidly evolving EV market and production processes. Hawkins et al. [8] and Nordelöf et al. [6] reviews acknowledged that the electricity production process within an LCA had the most significant impact on the variability of the results. As they reviewed studies published in 1997-2010 and 1998-2013, respectively, a need for an updated review and discussion of methods was identified, as this field of research continues to grow.

Marmiroli et al. [9] published a review discussing the conflicting results found in the literature due to methodological differences between studies regarding the electricity mix. Within their research, the GHG intensity of the electricity mix used to power the EV was estimated to be responsible for $70 \%$ of the variability within the reviewed studies' LCA results. The discussion within their research was then geared towards providing future studies with guidelines to improve consistency when accounting for electricity production. This study uses a standardized methodology for calculating emissions from energy production [10]. Combining the results from an up-to-date review of the most recent LCA 
literature, the goal is to perform a meta-analysis of the reviewed literature to estimate the effectiveness of EV integration in terms of GHG emissions across European countries.

The approach taken in this article is similar to that of Ellingsen et al. [11]. They performed an analysis across different vehicle segments using the EU electricity production mix and different electricity production technologies (i.e., coal, natural gas, wind). However, the research used relatively few sources to model vehicles, and did not provide comparable country-by-country results across the EU [11]. This study aims to bridge the gap left by the previous reviews and studies by providing both a review of the field of literature with feedback on the differences and variability within the methodologies and scopes of the studies, as well as a meta-analysis using life-cycle GHG data extracted from the studies, following Zamagni et al.'s approach [12]. This methodology will be used to answer the following research questions:

ReserachQuestion1: How do the existing published LCA studies comparing EVs and internal combustion engine vehicles (ICEVs), i.e., petrol or diesel vehicles, differ? (It is worth noting that all references to EVs within this paper refer to battery electric vehicles (BEVs); while plug-in hybrid electric vehicles (PHEVs) and fuel-cell electric vehicles (FCEVs) are an interesting field of study, they were considered outside the scope of this study).

ResearchQuestion2: How do the GHG intensities of the electrical grids across Europe affect EVs' environmental effectiveness?

By answering RQ1, this paper provides an up-to-date literature review, as well as an in-depth analysis of different EV LCAs, expanding upon the framework put out by Egede et al. [5]. The goal was to gain a deeper understanding of reasons for variability — for example, in terms of scope, battery size, vehicle weight, lifetime, and electricity source-to identify potential research needs and priorities for future LCAs. Additionally, this work allowed the study to consider the variation in individual studies' outcomes to perform a cross-study meta-analysis to answer RQ2. It allowed for a set of statistics for the life-cycle phases of a vehicle to be collected. A standardized cross-country comparison was made using a standardized set of electrical grid GHG intensities across the European Economic Area (EEA) countries. It could not have been done by merely looking at individual specific-country-focused LCA studies and comparing them. Based on the results, policies regarding life-cycle emissions across EEA countries with different grid conditions were then discussed.

EVs' environmental effectiveness across Europe is estimated by calculating the distance of intersection points (DIP) for the EEA countries using the EV emission estimates from the literature review. The DIP represents the estimated number of kilometers that would need to be driven by an EV and the comparison ICEV so that the total life-cycle emissions of each vehicle type would be equal, as performed in previous studies $[11,13]$. The emission disparity (ED) between the compared vehicles within each DIP analysis was calculated to estimate the total life-cycle GHG emission impacts of using an EV compared to a petrol or diesel vehicle. The maximum production emissions (MPEs) that an EV can reach before losing environmental viability were additionally estimated. A Monte Carlo simulation was then performed as a sensitivity analysis to determine the probability that an EV would lead to less life-cycle GHG emissions with different electricity grid emission intensities according to the distribution of the data collected within the review.

The results of this study aim to further the discussion surrounding the environmental viability of EVs across the EEA in terms of GHG emissions from a life-cycle perspective. The policy discussion regards the soundness ofEEA countries' climate, transportation, and EV policies in the context of life-cycle emissions, reflecting on whether existing policies are in line with the techno-environmental reality of vehicle production emissions and electrical grid GHG intensities.

\section{Materials and Methods}

A mixed-method approach was followed in this study. First, a review of the field of EV LCA studies and a qualitative meta-analysis of the reviewed studies were performed, with the primary 
methodological aspects mapped and a gap analysis performed to understand where variation existed across the studies and where improvements were needed. Second, a quantitative meta-analysis was performed using the extracted life-cycle GHG emission data extracted from the reviewed studies. To standardize the use phase of the electric vehicles, which were highly dependent on the electrical grid, were highly unstandardized, and were a large source of variation in previous studies [9], a standardized method for estimating GHG emissions across the EEA was used [10]. It allowed for improved cross-study data-use applicability and a more policy-relevant output.

\subsection{EV LCA Review}

The EV LCA review was performed using the Standardized Technique for Assessing and Reporting Reviews of Life Cycle Assessment Data (STARR-LCA) checklist developed by Zumsteg et al. [14]. The well-established Preferred Reporting Items guided the formulation of this STARR-LCA checklist, or Systematic Reviews and Meta-Analyses (PRISMA) statement [15], from the field of medicine. It was adapted in Zumsteg et al.'s work for the use of LCA reviews. A qualitative LCA review approach suggested by Zamagni et al. [12] was then followed. The research question was defined, the literature review was performed, and the research gaps were finally identified, analyzed, and discussed. These frameworks were used as guides. They provided relevant frameworks for the specific research question at hand-specifically, a review and meta-analysis across the literature field for a specific product.

\subsubsection{Selection of Review Material}

The review material search process consisted of two steps: (1) a snowball process, meaning searching through the references of the papers known by the authors, their references, and so on, until no new papers were found fulfilling the selection criteria; (2) a database search through Science Direct, Scopus, Google Scholar, and Web of Science to complement the snowball collection. The primary search terms used were: "LCA of Electric Vehicles" and "Comparative LCA of electric vehicles", as well as a key term search for "Electric Vehicle" and "Life Cycle Assessment", leading to a collection of 25 papers.

The 25 studies found using this search were screened to see if they fulfilled the following selection criteria:

1. Published in the last ten years (the most dated study was 2012).

2. Included the production (material extraction and manufacturing) phase and use phase of the vehicle.

3. Included greenhouse gas emissions within the analysis.

4. Used empirical data.

5. Included a BEV case.

6. Included a medium-sized passenger vehicle.

Nineteen studies were found to fulfill the criteria, these forming the final review collection utilized in the remainder of the paper. A period of ten years was selected as the review period because of EVs being an emerging technology, and to see if changes could be seen within the last ten years of significant EV market growth. The necessity of including the production and use phase is because these phases account for $>95 \%$ of life-cycle emissions for EVs and ICEVs. Since this study aims to determine the amount of GHG emissions, all studies selected would need to include a GHG analysis. While plug-in hybrid electric vehicles (PHEVs), hybrid electric vehicles (HEVs), and fuel-cell electric vehicles (FCEVs) are interesting fields of study, PHEVs and HEVs are heavily dependent on the use case, and FCEVs were considered outside the scope of this study. Thus, only BEV studies were considered and included. The use of medium-sized passenger vehicles reduces the variability that would accompany data associated with sports utility vehicles (SUVs), trucks, vans, or other such larger vehicles to improve consistency. 


\subsubsection{Review Approach}

The chosen articles were reviewed for their goals and scopes, processes included within the life cycle, and determining factors, such as battery capacity and vehicle lifetimes. During this review, process data were extracted from each article to characterize and find trends within the results. The data were broken down into three categories (Table 1).

Table 1. Data extracted from the articles reviewed.

\begin{tabular}{ccc}
\hline Methodological Characteristics & Contextual/Vehicle Characteristics & Results \\
\hline Included life-cycle processes & Electricity mix & Battery production \\
Life-cycle assessment (LCA) type & Country of study & Vehicle production \\
(process, hybrid, or input-output (IO)) & Vehicle make/model & Total production \\
Background database & Well-to-Tank \\
Other data sources & Powertrain (ICEV, BEV, PHEV) & Tank-to-Wheels \\
& Vehicle weight & Well-to-Wheels \\
& Fuel efficiency (l/100 km and kWh/100 km) & End of life \\
& Battery capacity & Vehicle lifetime \\
& Vehicle classification (LDV, SUV, etc.) & Maintenance (including battery replacement) \\
& & Total life-cycle emissions \\
\hline
\end{tabular}

\subsection{Analysis}

After the review and qualitative meta-analysis, the quantitative meta-analysis was performed, in which the goal was to estimate the life-cycle GHG impacts of EVs through quantitative synthesis and statistical analysis of the extracted data following Zumsteg et al. [14] and Zamagni et al.'s [12] suggested approaches.

\subsubsection{The Distance of Intersection Point Calculations}

EVs are generally considered a mitigation method during the use phase of the vehicle. However, EVs are significantly more likely to have higher GHG emissions in the production phase of a vehicle life cycle versus a comparable ICEV vehicle, primarily due to the inclusion of EVs' emission-intensive battery pack (e.g., [16]). Figure 2 illustrates this relationship.

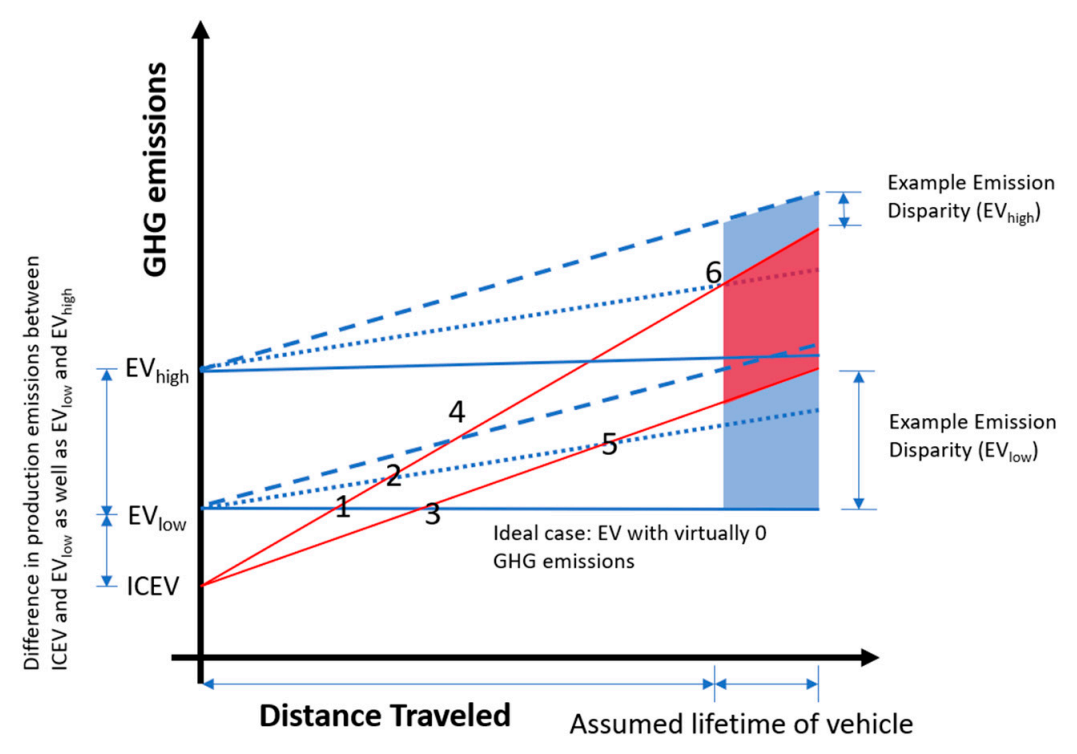

Figure 2. Potential distance of intersection points (DIP) of an internal combustion engine vehicle (ICEV), an electric vehicle (EV) with high production-phase emissions, and an EV with low production-phase emissions. The two red lines signify the different fuel efficiencies or types (i.e., diesel, petrol) of an ICEV. The blue lines signify the EVs' use phase emissions, with different electricity grid emission intensities; unbroken line: no associated emissions; dotted line: medium emission intensity; dashed line: high emission intensity. 
Each numbered point within Figure 2 identifies a different DIP (the breakeven point) for an associated vehicle comparison. For example, point 1 identifies a DIP reached after the shortest distance traveled, where an EV with low production emissions powered by a near emission-less source of electricity would reach the same level of life-cycle emissions as a less efficient ICEV. Point 5 identifies a DIP between a more fuel-efficient ICEV and an EV with low production emissions powered by a medium emission-intensive electricity grid. The vertical distance between two points can be considered as the emission disparity at that particular distance of comparison. This framework highlights the value of a breakeven analysis if EVs are considered a GHG mitigation solution and illustrates the high variability in cumulative GHG emissions that can be incurred over the lifetime of an EV compared to an ICEV. It sheds light on how quickly an EV can provide potential GHG emission reductions according to different conditions.

The DIP in kilometers can be calculated using the following formula:

$$
D I P=\frac{P E_{e v}-P E_{i c e v}}{\left(\left(W T W_{i c e v}+M_{i c e v}\right)-\left(W T W_{e v}+M_{e v}\right)\right)}
$$

where $P E_{e v}$ and $P E_{i c e v}$ are the production emissions in tons of $C_{2}$ equivalents for the EV and ICEV being studied, respectively. The $W T W_{i c e v} / W T W_{e v}$ and $M_{i c e v} / M_{e v}$ are the Well-to-Wheel (WTW) and maintenance GHG emissions of the studied ICEV or EV in tons of $\mathrm{CO}_{2}$ equivalents per kilometer (typically reported in grams of $\mathrm{CO}_{2}$ equivalents, but units were changed for use in the formula). The WTW emissions of an EV are estimated by multiplying the emission intensity of the electricity supplied with the assumed energy efficiency of the EV being studied.

\subsubsection{Emission Disparity}

The ED follows similar logic to that of the DIP, except that it represents the difference in life-cycle emissions at a specific distance driven, in this case, to estimate the life-cycle emissions from the production and use phases at the end of the studied vehicles' lifetimes. The emission disparity can be calculated using the following formula:

$$
E D=\left(P E_{i c e v}+\left(W T W_{i c e v}+M_{i c e v}\right) * L T+E O L_{i c e v}\right)-\left(P E_{e v}+\left(W T W_{e v}+M_{e v}\right) * L T+E O L_{e v}\right)
$$

Most inputs are similar to those of Formula (1), with the addition of $L T$, the estimated lifetime of the vehicle measured in kilometers, and $E O L_{i c e v}$ and $E O L_{e v}$, representing the $E O L$ emissions associated with each vehicle's recycling/disposal process type.

\subsubsection{Maximum Production Emissions}

The MPE measurement estimates the lowest level of production emissions of an electric vehicle necessary for an EV to be considered a mitigation solution over the EV's comparative life cycle and the compared ICEV. The MPEs, measured in $\mathrm{tCO}_{2} \mathrm{eq}$, can be calculated as follows:

$$
M P E=\left(P E_{i c e v}+\left(W T W_{i c e v}+M_{i c e v}\right) * L T+E O L_{i c e v}\right)-\left(\left(W T W_{e v}+M_{e v}\right) * L T+E O L_{e v}\right)
$$

where all inputs have been described after the previous formulas.

\subsubsection{Monte Carlo Simulation}

A Monte Carlo simulation was then performed using the range of meta-data extracted for each life-cycle phase found within the review. The total life-cycle emissions for each vehicle type were estimated within each simulation, repeated 100,000 times, and mapped across a range of electrical grid emission intensities, estimating the probability that an EV would lead to fewer GHG emissions than the compared ICEV counterpart. 


\subsubsection{GHG Emission Intensity of Electricity Supply}

The GHG emission intensity for each European country was sourced from Moro and Lonza [10], who provide a unified methodology that includes electricity trading between states. Additionally, we included GHG emission intensities of energy supplied in two EEA countries, Iceland and Norway, as they provide interesting cases with low-intensity electricity grids and strong push-policies for EV integration. For Norway, the calculation method and data presented by Moro and Lonza [10] were used, supplemented with simplified data on trade structure in 2018 (40\% with Sweden, $24 \%$ with Denmark, and $36 \%$ with the Netherlands). The resulting GHG intensity supplied is $29 \mathrm{gCO}_{2} \mathrm{eq} / \mathrm{kWh}$. For Iceland, the emission intensity of electricity used was assumed to be $20.7 \mathrm{gCO}_{2} \mathrm{eq} / \mathrm{kWh}$, as given in GaBi's global LCA database. These estimates were used for the WTT emissions and combined with the estimated energy efficiency of an EV to calculate the WTW emissions.

\section{Review}

\subsection{Overview of the Reviewed Studies}

Table 2 includes the information extracted from the 19 studies reviewed. The publication dates of the studies spanned from 2012-2019. The 19 studies compared 24 EVs against 24 ICEVs. There were $40 \mathrm{EV}$ cases from the 24 vehicles studied, with each case being defined by a specific EV paired with a specific grid condition. There were a total of 71 cases when summing EV and ICEV cases. As illustrated in Table 1, the included phases of the vehicle's life cycle varied between studies. The lifetime of the vehicles studied, measured in kilometers, was included to illustrate the different lifetime assumptions made within each study. This assumption then impacts the resulting emissions per functional unit $\left(\mathrm{gCO}_{2} \mathrm{eq} / \mathrm{km}\right)$, presented in Table A1 of Appendix A. Additionally, each study was identified as being a process, input-output, or hybrid LCA to determine if the utilized LCA method could lead to additional variability in results, which is elaborated upon in the discussion section.

Three primary categories of causes of variation between each study's results were identified: (1) differences in methodologies, goals, and scopes, (2) contextual variability and assumptions, and (3) differences in levels of granularity and access to data. These categories are explored further in the following subsections.

\subsection{Methodologies, Goals, and Scopes}

While all papers within the review presented an LCA on EV passenger vehicles, distinct methodologies, scopes, and goals existed among them. The lack of clear goals has been documented in previous reviews [6,9], and was again identified in this review, along with differences in included life-cycle phases and details within them despite the framework provided by Egede et al. [5]. There was no evident improvement in terms of clear goals, scopes, or inclusion of life-cycle phases over time since these publications. One of the most significant inconsistencies was related to life-cycle phase/component inclusion, particularly EOL and battery replacement. It could be due to a lack of available data on recycling technologies, as EVs have only recently entered the mass market, and these new entrants have yet to reach their end of life. As part of the selection criteria, all papers were required to include the production- and use-phase life-cycle processes. Still, the inclusion of other life-cycle phases (and components in the case of battery replacement) varied. The following subsections further describe the critical methodological, goal, and scope differences between the studies.

\subsubsection{Inclusion of Battery Replacement}

The inclusion of battery replacement serves as a good example of the methodological differences between studies. There were essentially six approaches taken towards the inclusion of battery replacement within the LCA studies reviewed, which are presented in Table 3. 
Table 2. The data on studies captured in the review with the included factors listed by year of publication.

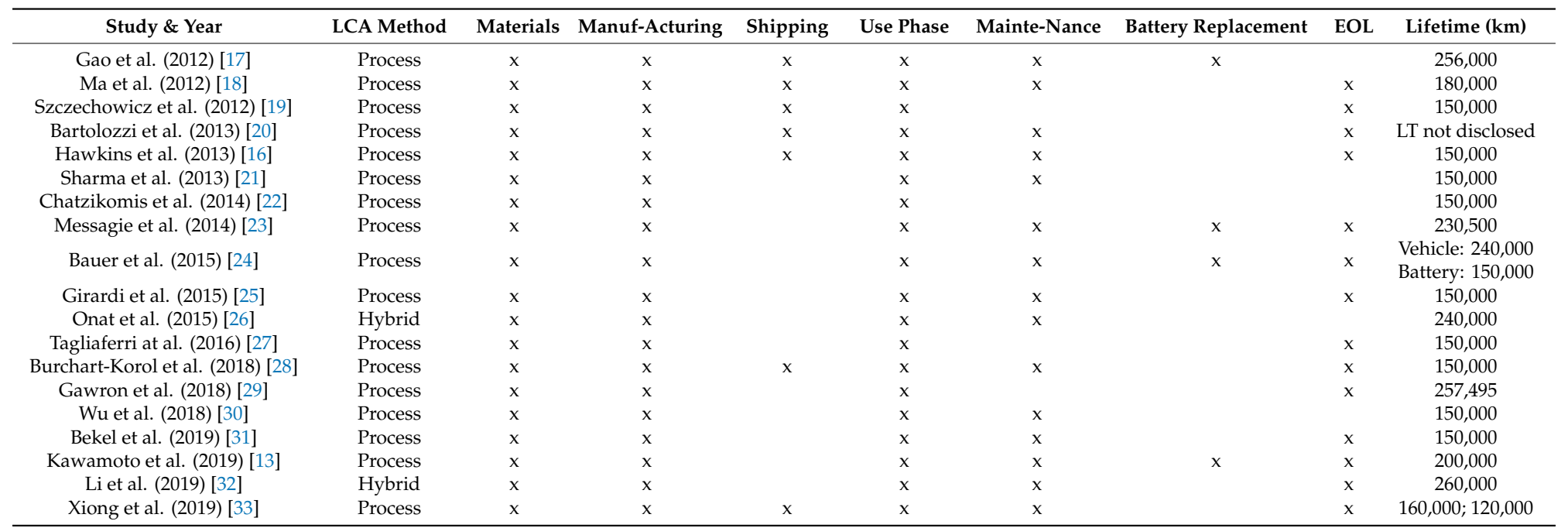

Table 3. Approaches to battery replacement.

\begin{tabular}{ccc}
\hline Approach & Number of Studies & Studies \\
Not discussed and not included & 6 & 1 \\
Out of scope-identified as a limitation & 7 & {$[20-22,29,31,32]$} \\
Battery life considered longer than or equal to vehicle life & 2 & {$[18]$} \\
Battery replacement included with unclear methodology & 1 & $1,19,25-28,30,33]$ \\
Included with clear methodology-Ratio of battery lifetime versus EV lifetime & 1 & {$[23]$} \\
Included with clear methodology-one-time battery replacement & {$[13]$} \\
\hline
\end{tabular}




\subsubsection{Inclusion of End of Life}

The inclusion of EOL was one of the methodological differences with the highest variation within the review. There were five primary approaches taken towards EOL within the LCA studies reviewed, which are presented in Table 4.

Table 4. Approaches taken to end of life (EOL).

\begin{tabular}{|c|c|c|c|}
\hline Approach & Additional Comments & Number of Studies & Studies \\
\hline $\begin{array}{l}\text { Not discussed and } \\
\text { not Included }\end{array}$ & & 1 & {$[22]$} \\
\hline $\begin{array}{l}\text { Out of scope-identified } \\
\text { as a limitation }\end{array}$ & $\begin{array}{l}\text { Limitations often mention lack of precedence due } \\
\text { to mass-market EVs not having reached EOL or } \\
\text { citing relative impact being less than } 2 \% \text { of total } \\
\text { life-cycle emissions in studies that have included } \\
\text { EOL. }\end{array}$ & 3 & {$[21,26,30]$} \\
\hline $\begin{array}{l}\text { Included with an } \\
\text { unclear methodology }\end{array}$ & $\begin{array}{l}\text { Aggregated EOL emissions into other processes, } \\
\text { making the environmental impact associated with } \\
\text { EOL unclear. Because EOL often includes recycling } \\
\text { materials, uncertainty increases because recycling } \\
\text { can lead to positive or negative GHG emissions } \\
\text { depending on methodology. }\end{array}$ & 4 & {$[17,24,28,31]$} \\
\hline $\begin{array}{l}\text { Included with clear } \\
\text { methodology-positive } \\
\text { environmental impact }\end{array}$ & $\begin{array}{l}\text { Positive environmental impact in terms of reducing } \\
\text { GHG emissions due to material recycling. }\end{array}$ & 2 & {$[23,27]$} \\
\hline $\begin{array}{l}\text { Included with clear } \\
\text { methodology-negative } \\
\text { environmental impact }\end{array}$ & $\begin{array}{l}\text { a. Direct calculations of EOL emissions } \\
\text { b. Partial inclusion of EOL, often only taking } \\
\text { energy use within recycling/disposal process } \\
\text { into account } \\
\text { c. Scaling factor of production emissions due } \\
\text { to uncertainty in EOL processing }\end{array}$ & 9 & $\begin{array}{l}{[16,19,20,25,29,32]} \\
{[13,33]} \\
{[18]}\end{array}$ \\
\hline
\end{tabular}

3.2.3. Inclusion of Maintenance and Differing Sub-Process Inclusion within the Maintenance Phase

The inclusion of maintenance had variability in including the life-cycle phase itself and sub-processes within the maintenance life-cycle phase. There were four primary approaches taken towards the inclusion of maintenance within the LCA studies reviewed, which are presented in Table 5.

Table 5. Approaches taken to maintenance.

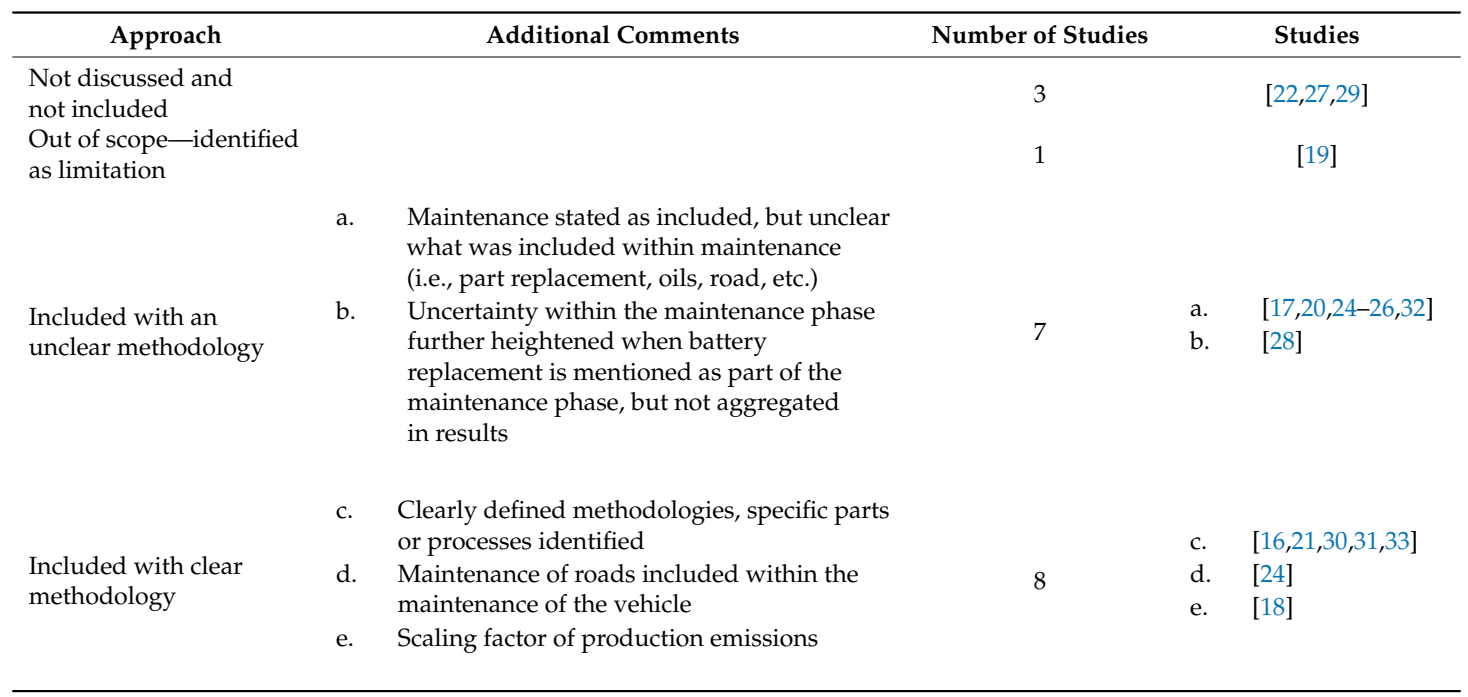

\subsubsection{LCA Methods}

Of the reviewed studies, $90 \%$ performed process LCAs, and the remaining two studies [26,32] performed hybrid LCAs. None solely performed an input-output (IO) LCA. Process LCAs most 
typically would develop the Life Cycle Inventories (LCIs) upstream until all vehicle parts were broken down to the comprising materials. At that point, most of the studies would then connect these materials to background databases. The hybrid LCAs performed a similar analysis, except the material breakdowns were then applied to an IO database, combining the benefits of a process LCA and an IO LCA [34,35], assisting in the elimination of the truncation error inherent in process LCAs. Examples from other sectors show that IO LCAs typically produce higher emission estimates because of eliminating this truncation error and the inclusion of capital goods and overheads [36,37].

\subsubsection{Databases Used for Background Data}

As mentioned, process LCAs most typically connect material and energy inputs to a background LCA database to populate the inputs and outputs required for the associated processes. Table 6 shows which databases were utilized within each study. It is worth noting that many studies used a combination of the databases mentioned and primary data across their respective analyses. Therefore, the role of the database within the analysis cannot precisely be determined without detailed supplementary data.

Table 6. Databases/data sources used within each study.

\begin{tabular}{ccc}
\hline Database/Data Source & Number of Studies & Studies \\
\hline Ecoinvent & 7 & {$[19,20,24,25,27,28,31]$} \\
GREET & 5 & {$[16,17,21,26,29]$} \\
Collection of published data and/or country-specific databases, Other & 6 & {$[13,18,22,23,30,32]$} \\
GaBi & 1 & {$[33]$} \\
\hline
\end{tabular}

The selection of a database can lead to variability due to differing database methodologies. This was recently highlighted in a study that found that emissions associated with battery production differed significantly depending on whether the material inputs were connected to GREET, Ecoinvent, or thinkstep GaBi databases [38]. Variability caused by using different background databases has been seen in other sectors, such as the construction sector [39].

\subsubsection{Drive Cycle Selection}

The drive cycle used within each study can impact the environmental performance of the vehicles being analyzed, as it defines the fuel/energy efficiency of the vehicles being studied, which, in turn, impacts the emissions associated with a vehicle's use phase. Around $50 \%$ of the reviewed studies either simply defined the efficiency and/or did not mention any form of drive cycle under which these efficiencies were tested [13,16,19,21,25,27-32]. Around 30\% used the New European Driving Cycle (NEDC) $[16,18,19,23,25,27]$.

The remaining studies made use of other drive cycles, such as the Worldwide harmonized Light vehicles Test Procedure (WLTP), Australian Urban Drive Cycle (AUDC), and Urban Dynamometer Driving Schedule (UDDS) [18,21,24].

\subsection{Contextual Variability and Assumptions}

The second category of variability factors relates to the context of the study. It primarily concerns the vehicle's attributes under study and the life-cycle emissions associated with the power source, particularly in terms of GHG emission intensity of the assumed electricity source. The following subsections discuss each of the contextual factors that can impact the results of a vehicle LCA. It is worth noting that there may be a varying number of cases within each analysis within the following subsections due to missing data points in the studies reviewed, which in itself is one of the identified sources of result variability.

\subsubsection{Electricity Source}

The assumed electricity supply within the study played a significant role in determining the WTW emissions, which affected the results. Studies that performed their analyses on regions with high 
coal use levels within their electricity grid, such as China, had significantly higher WTW emissions than others that assumed entirely wind or hydroelectric power sources. Figure 3 shows the WTW results of different cases, highlighting this disparity. Marmiroli et al. [9] covered this topic in great detail. Thus, this paper acknowledges the variance in methodologies, selected grids, and technologies and its importance, but will not discuss this in more detail for brevity.

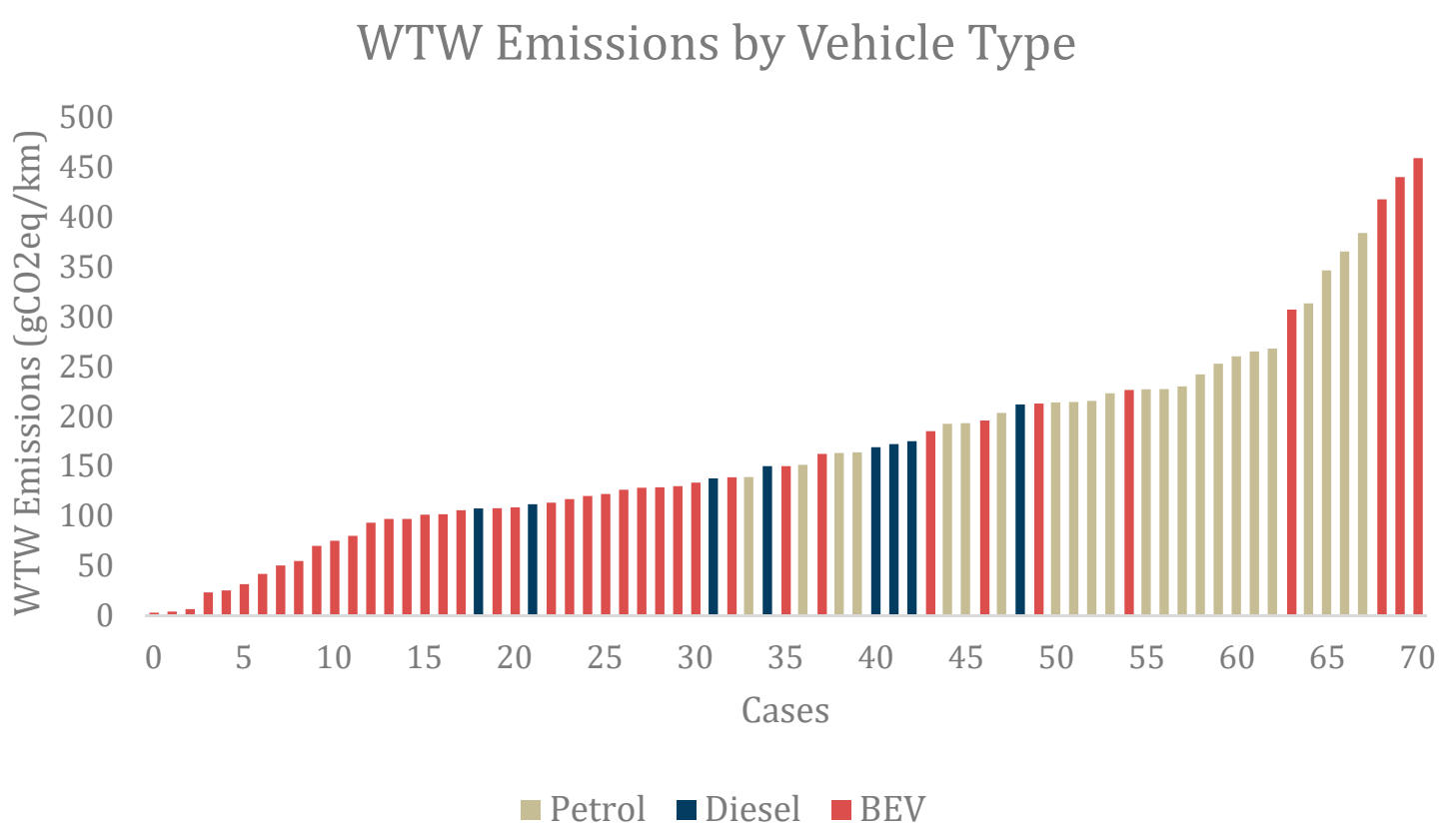

Figure 3. WTW emissions $\left(\mathrm{gCO}_{2} / \mathrm{km}\right)$ by case.

\subsubsection{Production Location and Carbon Intensity of the Electrical Grid at the Production Facility}

When discussing location within the focus of contextual variability, most often and rightly so, the attention is drawn to the location of the use phase of the EV and emission intensity of the electricity grid powering it. However, the emission intensity of the electricity grid also plays a role in manufacturing. The International Council of Clean Transportation estimated that the electricity source used to manufacture EV battery packs is responsible for approximately half of the emissions associated with battery production [40]. Therefore, the battery production facility location (and the vehicle body, if the manufacturing locations of these two components differ) and the emissions associated with electric power play a significant role in the production process's final life-cycle GHG results. This geographical importance in the production stage (or, at least, the electricity source's carbon intensity, which often comes in hand) can be attributed to all phases of a vehicle's production process. A recent study found that 37 materials found in automobile manufacturing have significant variance in the production's electrical grid emission intensity [41]. It further highlighted the potential for variance across studies according to the time of production and assumed material and energy requirements.

\subsubsection{Battery Capacity}

Battery capacity can play a role in determining the life-cycle emissions of an electric vehicle. Of the 17 articles that stated a battery capacity, 21 cases of EVs and total production emissions are graphed in Figure 4 to highlight the correlation between battery capacity and estimated production emissions across the studies. As a vehicle's battery capacity increases, the associated vehicle's production emissions can be expected to rise, although with high variance due to the role of varying grid GHG intensity in the global battery supply chain. The average battery capacity from all EVs studied within this review was $30.5 \mathrm{kWh}$. 


\section{Battery Capacity and Associated Vehicle Production Emissions}

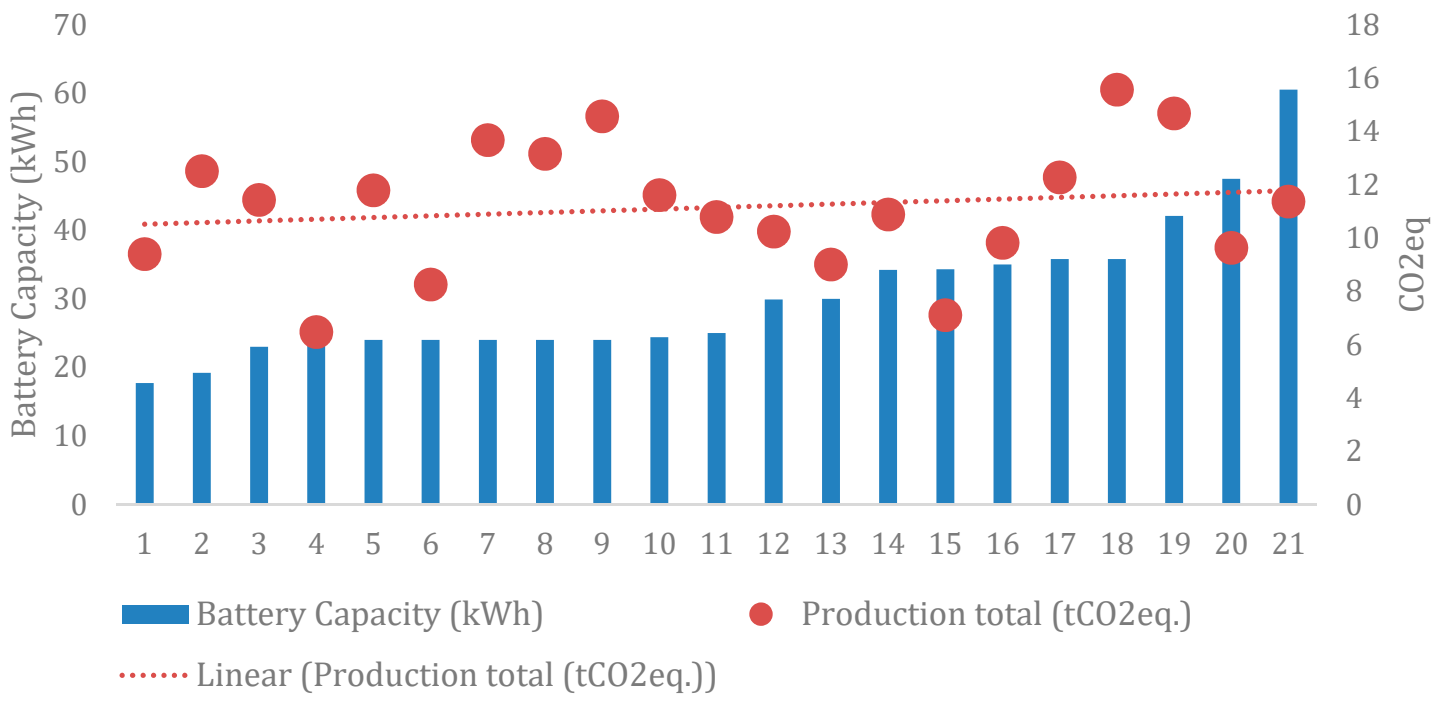

Figure 4. Battery capacity ( $\mathrm{kWh}$ ) and associated vehicle production emissions $\left(\mathrm{tCO}_{2} \mathrm{eq}\right)$.

\subsubsection{Vehicle Lifetime}

A vehicle's lifetime plays a role in determining the duration of the use phase. It acts as a divisor when calculating the life-cycle emissions per kilometer, with the most commonly used functional unit being grams of $\mathrm{CO}_{2}$ per kilometer driven - the greater the lifetime, the lower the per-kilometer emissions for the production and EOL phases. Of the 19 studies reviewed, the lowest assumed lifetime was $120,000 \mathrm{~km}$ and the highest assumed lifetime was $260,000 \mathrm{~km}$. The average lifetime between all cases was approximately $184,000 \mathrm{~km}$. There was no distinct trend of assumed lifetimes, as they depended on specific locations. However, some US studies assumed a lifetime in miles in the same quantity that other studies assumed in kilometers, leading to a significantly longer lifetime when converting units—an issue indicating the relatively arbitrary nature of the lifetime assumption.

\subsubsection{Energy Efficiency}

Energy efficiency defines the amount of electricity required to drive a vehicle an $X$ number of kilometers. Several units were reported within the studies reviewed, but the most standardized unit was $\mathrm{kWh} / 100 \mathrm{~km}$. The average fuel efficiency was calculated to be $16.7 \mathrm{kWh} / 100 \mathrm{~km}$.

\subsubsection{Vehicle Weight}

Vehicle weight is a factor worth considering when estimating the life-cycle emissions from vehicle production, as higher material requirements can typically be associated with higher emissions. All cases in which vehicle weight were specified are graphed in Figure 5 along with the production emissions. According to the reviewed studies' data, a trend with a high level of variability exists; production emissions increase as vehicle weights increase.

\subsection{Granularity and Access to Data}

The third category of variability factors identified was related to the granularity and access to data within the studies. While some granularity issues can be attributed to differences in the goal and scope defined within each study, the severity of the differences justifies this separation of categories. The lack of LCIs and background data in the research makes cross-study comparisons difficult, a fact noted in Hawkins et al. [8] EV LCA review. Hawkins et al. [16], therefore, published a vehicle LCA 
with supporting data with a breakdown of specific car components and further detail into each component [16]. While this provided a robust and thorough LCI and data source, unfortunately, it did not set the trend, and lack of data transparency and access to data have been a persistent issue in EV LCAs. Key examples in which granularity and access to data led to increased uncertainty are described in the following subsections.

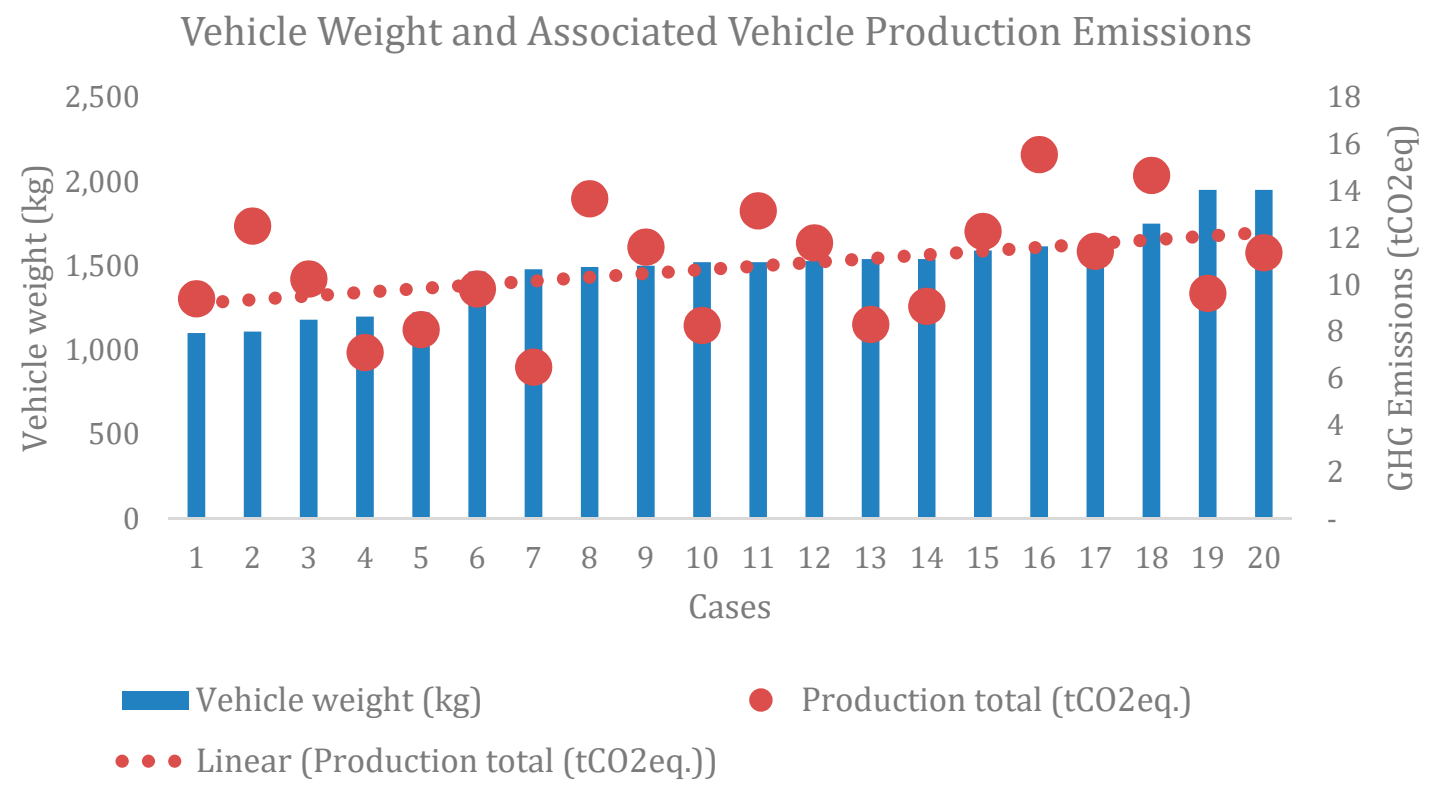

Figure 5. Vehicle weight $(\mathrm{kg})$ and associated vehicle production emissions ( $\left.\mathrm{tCO}_{2} \mathrm{eq}\right)$.

\subsubsection{Aggregated Emissions}

Aggregation of emissions with a lack of transparency in how the emissions were estimated was widespread among the reviewed studies. It was one of the most significant causes of uncertainty when reviewing the results of each study. It follows from the previous subsection, where even if battery replacement was stated as being included, aggregating battery replacement into production or maintenance emissions—as in $[17,24]$ —makes the impacts associated with the inclusion of battery production unclear. This issue of stating the inclusion of a particular process but not disaggregating the results was highly prevalent for the EOL phase $[17,24,28,31]$ and the maintenance phase $[17,24,25]$.

\subsubsection{Battery Pack Production Emissions}

The aggregation or non-stated emissions associated with battery pack production are a particularly important subset of the previous subsection on the issue of aggregated results, meriting their discussion. The inherent issue with the lack of transparency and access to data within the production phase, particularly concerning battery packs, is illustrated in Figure 6. This figure displays the production emissions by vehicle type (in $\mathrm{tCO}_{2} \mathrm{eq}$ ) collected from the reviewed studies, where it is evident that emissions from ICEV vehicles have low variability compared to BEVs. Figure 6 shows BEVs' production emissions, with battery production disaggregated from all other components when data were available. The lack of inclusion of the battery pack component, which can play a significant role in the total production emissions of an EV, highlights how a lack of transparency within the data can lead to uncertain results when attempting to analyze the research field.

\subsubsection{Lack of Supplementary Data}

The aggregation issue could potentially be solved with supplementary data with specific LCI and disaggregated result data. However, only three studies provided detailed enough data for a meaningful result analysis $[16,24,31]$. Some studies included supplementary data such as Life cycle 
impact assessment (LCIAs), but the data did not provide a meaningful by-component breakdown to allow for high comparability $[18,26,27,29]$. All other studies (63\% of studies reviewed) did not provide supplementary data.

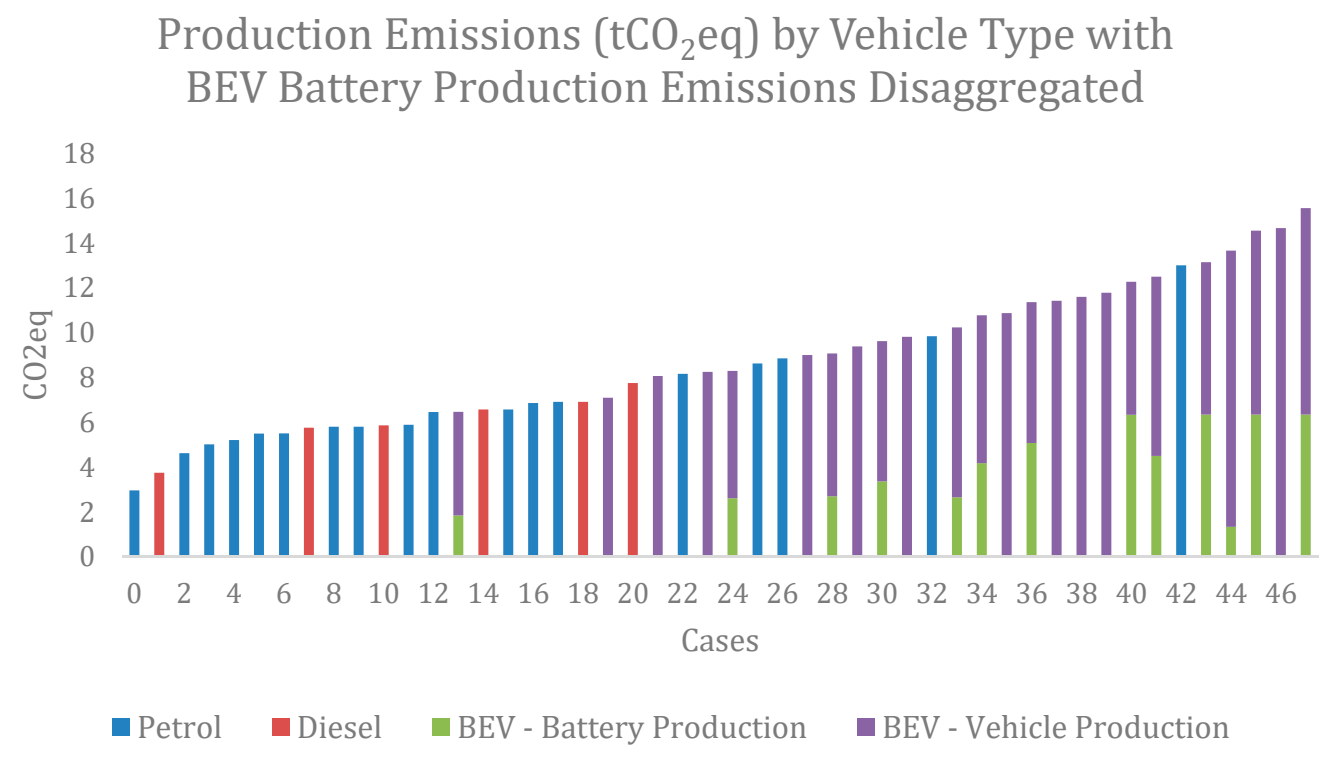

Figure 6. Production emissions ( $\left.\mathrm{tCO}_{2} \mathrm{eq}\right)$ by vehicle type, with BEV battery production emissions disaggregated when possible.

\subsubsection{Missing or Excluded Key Data Points}

Some articles contained missing or excluded key data points, which made cross-study comparisons difficult. For example, two studies did not include the energy efficiency of the vehicles being studied $[24,26]$, which plays a crucial role in the use phase in a vehicle's LCA. Other studies did not include the battery pack capacity $[23,30]$ or vehicle weight $[20,22,24]$, which can both indicate potential sources of variation in production emissions.

\section{Operationalization of Extracted Meta-Data}

The life-cycle-phase GHG emissions were extracted from each study for EVs and petrol and diesel vehicles to complete the quantitative meta-analysis used to answer RQ2. The DIP, ED, and MPE calculations were then performed as described in the methodology (Sections 2.2.1 and 2.2.2), and a Monte Carlo analysis was performed as a sensitivity analysis (Section 2.2.3).

\subsection{Aggregation of Results from All Studies}

Table 7 shows the mean, standard deviation (SD), and sample size $n$ cases for the vehicle types studied within the collected research. Table A1 is included as an appendix with all case data used for the calculations in Table 7. The changing sample size per life-cycle phase is due to the lack of data inclusion and transparency discussed in the previous sections. On average, BEVs had higher GHG emissions within the production-phase emissions. The standard deviation within the production emissions of both BEV and petrol vehicles highlights the importance of LCIs and background data regarding the vehicles' materials and production locations, as highlighted in Figures 5 and 6. These characteristics can play a decisive role in determining the outcome of comparative vehicle LCA studies. The WTW emissions associated with BEVs can be found in Table 7, and the different electricity sources assumed within each study help to explain the large variance of the WTW emissions. It is worth noting that diesel vehicles' sample size was relatively small $(n=6)$, as diesel vehicles were less often compared to EVs than petrol vehicles. This small sample size leaves room for bias, which will be discussed to a greater extent within the limitations section, Section 4.3. 
Table 7. Mean, standard deviation (SD), and population size $n$ of emissions from production, WTW, maintenance, EOL, and energy efficiency from all studies reviewed.

\begin{tabular}{|c|c|c|c|c|c|c|}
\hline & & $\begin{array}{l}\text { Production } \\
\left(t \mathrm{CO}_{2} \text { eq. }\right)\end{array}$ & $\begin{array}{l}\text { Energy Efficiency } \\
\text { (EV: } \mathrm{kWh} / 100 \mathrm{~km} \\
\text { ICEV: } \mathrm{L} / 100 \mathrm{~km})\end{array}$ & $\begin{array}{c}\text { WTW } \\
\text { Emissions } \\
\left(\mathrm{gCO}_{2} \text { eq } / \mathrm{km}\right)\end{array}$ & $\begin{array}{l}\text { Maintenance } \\
\left(\mathrm{gCO}{ }_{2} \mathrm{eq} / \mathrm{km}\right)\end{array}$ & $\begin{array}{c}\mathrm{EOL} \\
\left(t \mathrm{CO}_{2} e q\right)\end{array}$ \\
\hline \multirow{3}{*}{ BEV } & Mean & 10.8 & 16.7 & 132.2 & 10.1 & 0.2 \\
\hline & $\mathrm{SD}$ & 2.38 & 3.15 & 107.1 & 5.06 & 1.55 \\
\hline & $n$ & 24 & 23 & 40 & 14 & 13 \\
\hline \multirow{3}{*}{ Petrol } & Mean & 6.6 & 7.6 & 237.1 & 12 & 0.4 \\
\hline & SD & 2.01 & 2.12 & 63.64 & 5.55 & 1.05 \\
\hline & $n$ & 18 & 17 & 23 & 12 & 14 \\
\hline \multirow{3}{*}{ Diesel } & Mean & 6.1 & 5.2 & 154.3 & 10.1 & -0.6 \\
\hline & SD & 1.25 & 1.03 & 32.7 & 4.82 & 1.06 \\
\hline & $n$ & 6 & 5 & 8 & 4 & 4 \\
\hline
\end{tabular}

\subsection{Electrical Grid Intensities}

Utilizing the electrical grid GHG intensities as described in Section 2.2.4., the countries with the lowest and highest electric emission intensity were Iceland and Latvia, estimated to be 20.3 and $1168 \mathrm{gCO}_{2} \mathrm{eq} / \mathrm{kWh}$, respectively. The European Union's electric grid was estimated to have an average intensity of $447 \mathrm{gCO}_{2} \mathrm{eq} / \mathrm{kWh}$, which is relatively consistent with other published literature [42]. The average value for energy efficiency for EVs found within the review analysis, $16.7 \mathrm{kWh} / 100 \mathrm{~km}$, was used to perform the calculations in the following subsections (petrol and diesel vehicles additionally used the average efficiency values, in $\mathrm{L} / 100 \mathrm{~km}$, found for the associated vehicle type found in Table 7). The average distance driven over the vehicle's physical lifetime in all reviewed studies was $183,894 \mathrm{~km}$, which is thus used as the lifetime within the following analysis. The impacts of changes in these values, energy efficiency, and lifetime are looked into in Sections 3.2.3 and 3.2.4 and examined further in the discussion section.

\subsection{The Distances of Intersection Points (DIPs)}

The resulting DIPs, according to the calculations in Equation (1) and using the inputs described in Section 4.1, are shown in Figure 7.

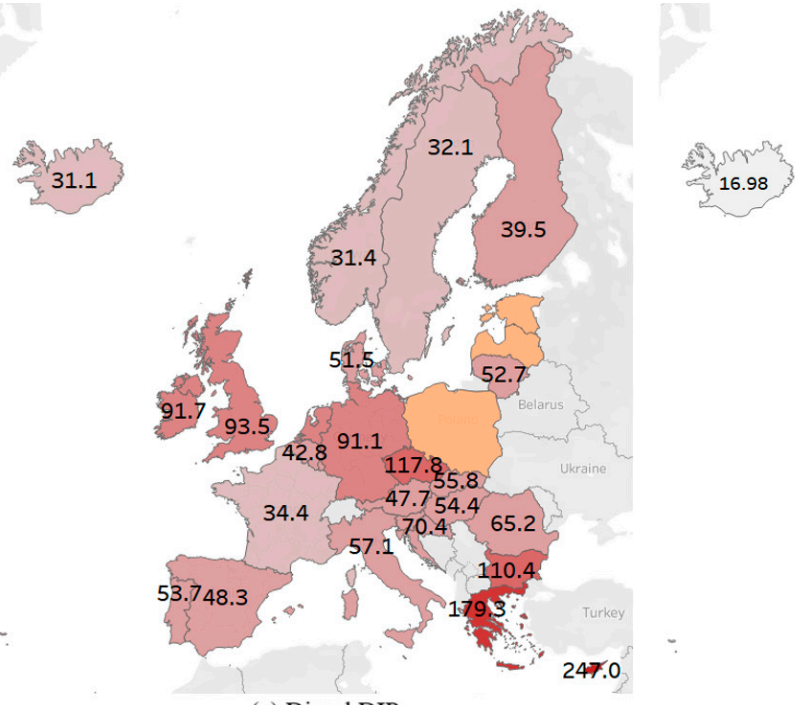

(a) Diesel DIP

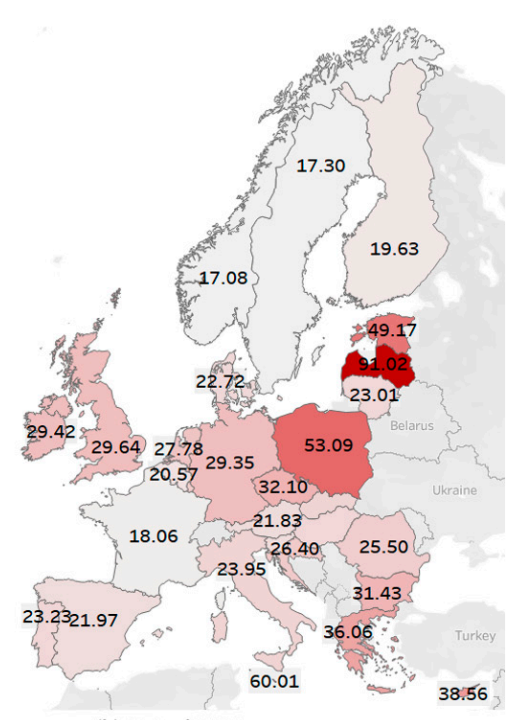

(b) Petrol DIP

Figure 7. The distances of intersection points (DIPs; measured in thousands of kilometers) between an EV and (a) a diesel vehicle for comparison; (b) a petrol vehicle for comparison (in Figure 7a, the diesel DIP case, Malta does not intersect, and is thus highlighted in orange, but cannot be seen due to its relative size on the map). 
Figure 7a shows the calculated DIPs for the diesel case. In the countries colored in orange and with no labeled DIPs (Poland, Estonia, Latvia, and Malta), BEVs would never intersect with the compared diesel vehicle at the current electric grid emission intensity due to the use-phase emissions of the BEV being higher than those of the diesel vehicle. Additionally, only Cyprus saw breakeven points beyond the vehicles' assumed lifetime. The darker red the country, the greater the number of kilometers required to be driven to meet the DIP point. In the petrol case (Figure 7b), no countries saw a DIP greater than the vehicles' assumed lifetime. The minimum estimated DIPs were approximately 31,100 and 17,000 km for the diesel and petrol cases, respectively, which were both found in Iceland. France and the other Nordic countries follow not far behind Iceland.

\subsection{Emissions Disparity (ED)}

The ED, the difference in life-cycle emissions at the end of the vehicle lifetime, according to the calculations found in Equation (2) and using the inputs described in Section 4.1, are shown in Figure 8.

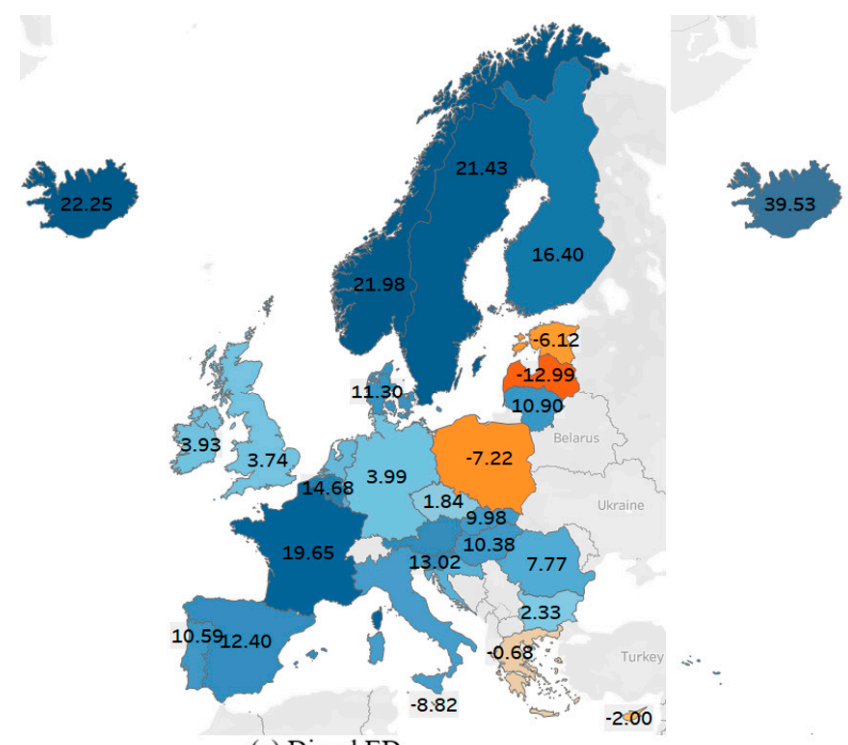

(a) Diesel ED

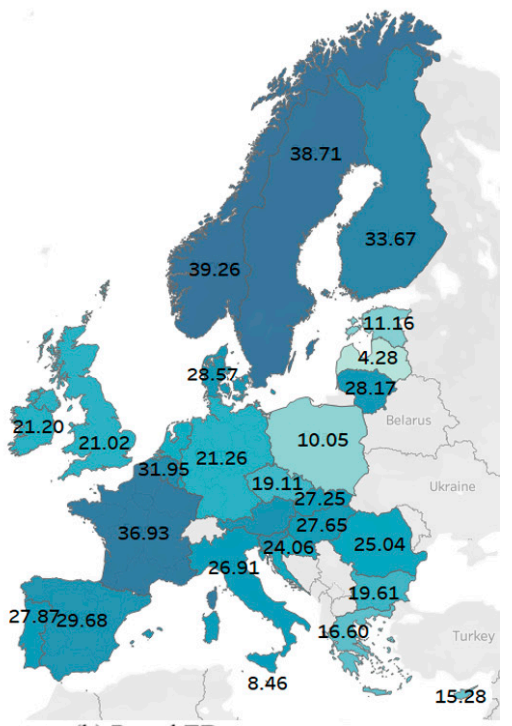

(b) Petrol ED

Figure 8. Emissions disparity (ED) (measured in $\mathrm{tCO}_{2} \mathrm{eq}$ ) between an $\mathrm{EV}$ and (a) a diesel vehicle for comparison; (b) a petrol vehicle for comparison.

Figure 8a shows that in comparison with diesel vehicles, EVs are estimated to have more GHG emissions over their life cycle in seven countries. All countries that are not blue have a negative ED (Latvia, Estonia, Poland, Greece, Cyprus, and Malta). The diesel case's lighter blue countries show countries where EVs will lead to less GHG emissions, but the mitigation effect is less significant. In the petrol case, EVs were estimated to result in less life-cycle GHG emissions than the compared petrol counterparts in all countries However, the mitigation potential differs between countries, where the darkest blue color represents countries with the largest mitigation potential.

\subsection{Maximum Production Emissions (MPEs)}

The MPEs according to the calculations found in Equation (3) and using the inputs described in Section 4.1, are shown in Figure 9.

The MPEs represent the highest GHG emissions associated with producing an EV permissible for the EV to be considered a GHG mitigation solution. Within the diesel case, it can be seen that the only non-blue colored country is Latvia, where a negative MPE would be required to be environmentally viable, which is obviously an unrealistic case. On the other end, within the petrol case, all countries showed very high MPEs. There are multiple countries within the 1.5 standard deviations range (7.23-14.37 $\mathrm{tCO}_{2} \mathrm{eq}$ ) from the mean EV production emissions within the diesel case. 


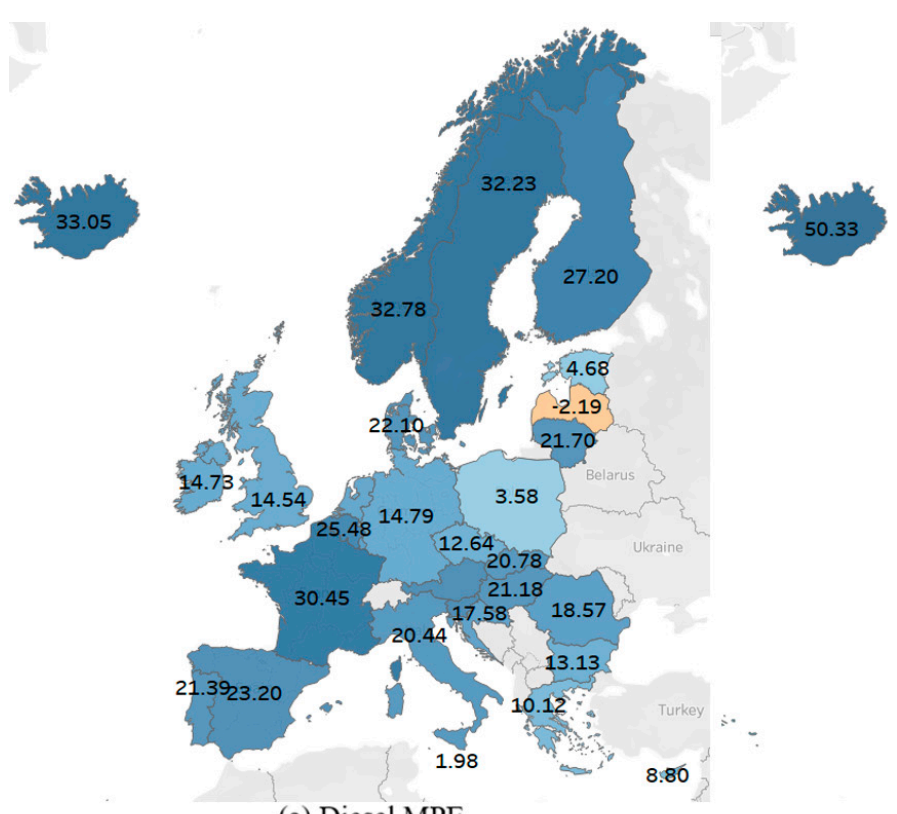

(a) Diesel MPE

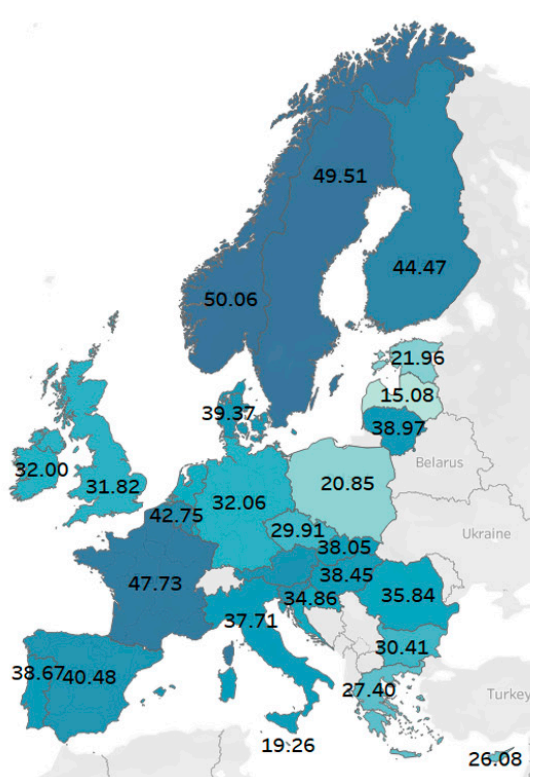

(b) Petrol MPE

Figure 9. Maximum production emissions (MPEs; measured in $\mathrm{HCO}_{2} \mathrm{eq}$ ) of an EV to environmentally outperform (a) a diesel vehicle for comparison; (b) a petrol vehicle for comparison.

\subsection{Monte Carlo Simulation (MCS)}

A Monte Carlo simulation was performed 100,000 times to estimate the life-cycle GHG emissions for each vehicle type within each simulation. It used the mean and standard deviation values for each life-cycle phase, and different EV energy efficiencies (ICEV energy intensities were taken into account within the variation of Tank-to-Wheel (TTW) emissions). The probability that an EV would lead to less GHG emissions than the compared ICEV was mapped at intervals of $20 \mathrm{gCO}_{2} \mathrm{eq} / \mathrm{kWh}$. The results of this simulation are presented in Figure 10.
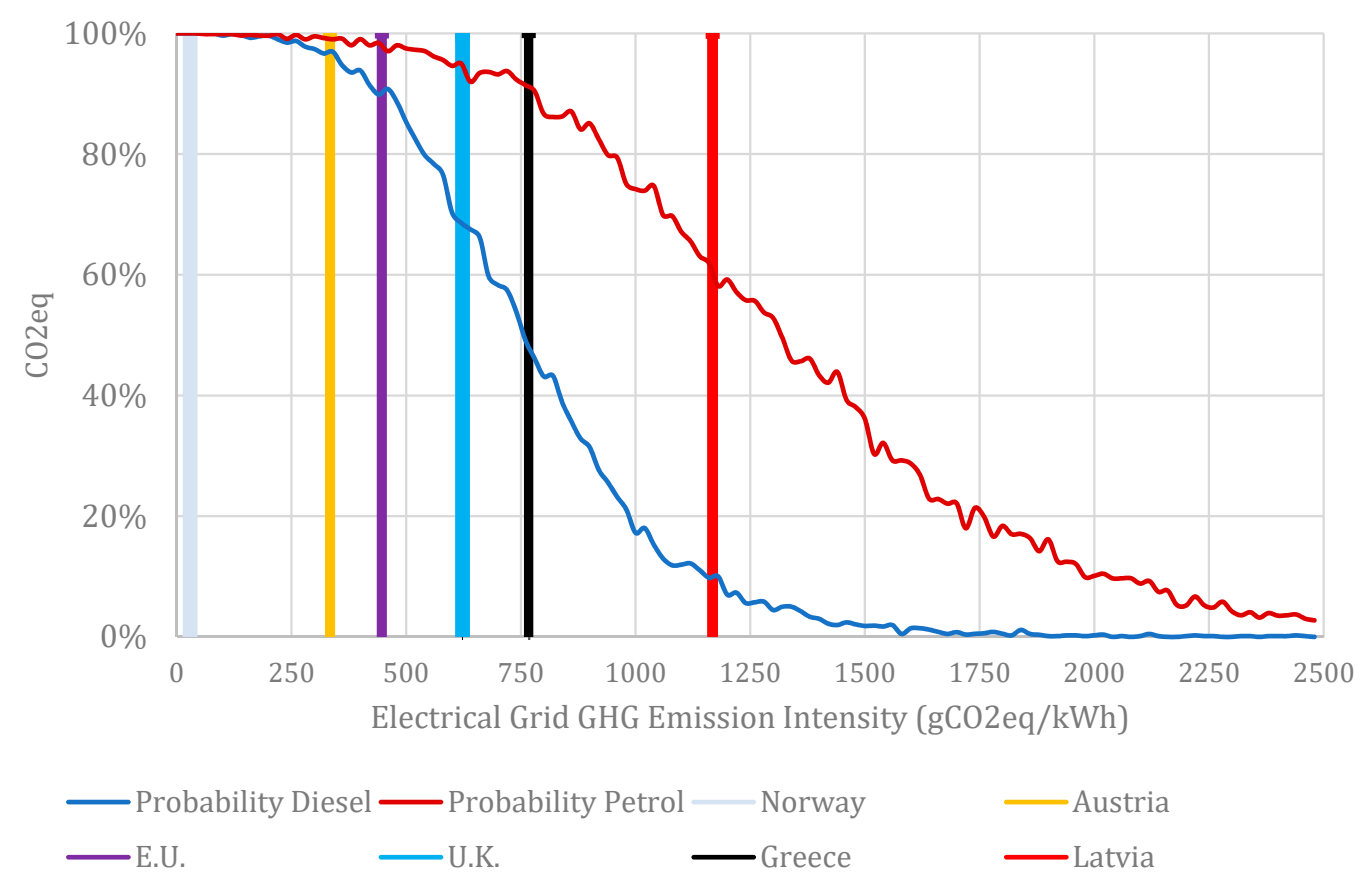

Figure 10. Monte Carlo simulation of the probability that EVs lead to lower life-cycle emissions than ICEVs for different electrical grid greenhouse gas (GHG) emission intensities. The blue line is compared to diesel and the orange compared to petrol. 
Several countries were graphed on top of the probability curves according to their associated electrical grid emission intensities to illustrate the approximate probability of an EV leading to fewer GHG emissions than its compared ICEV counterpart. The results show that the higher the electrical grid emission intensity, the lower the likelihood of an EV leading to fewer GHG emissions. For diesel vehicles, at approximately $300 \mathrm{gCO}_{2} \mathrm{eq} / \mathrm{kWh}$, a probability that EVs could lead to greater GHG emissions begins to develop. Between 500 and $1000 \mathrm{gCO}_{2} \mathrm{eq} / \mathrm{kWh}$, the bulk of the drop in an EV's probability of outperforming a diesel vehicle is seen. While the EU average grid was estimated to have a GHG intensity of $447 \mathrm{gCO}_{2} \mathrm{eq} / \mathrm{kWh}$, the marginal electricity production emissions could be significantly higher than the average [43]. As will be discussed further in the "Limitations and Further Study" section, this increased grid GHG intensity would likely decrease EVs' probability of leading to lower life-cycle GHG emissions. When compared to petrol vehicles, EVs see a slower drop in probability, with the probability of an EV leading to greater GHG emissions than a petrol vehicle existing on the far end of the spectrum of GHG emission intensities of an electrical grid. Figures 11 and 12 include EEA countries grouped by these probabilities for diesel and petrol vehicles, respectively. The calculated probabilities for each country's diesel and petrol vehicles can be found in Figure A1 in Appendix A.

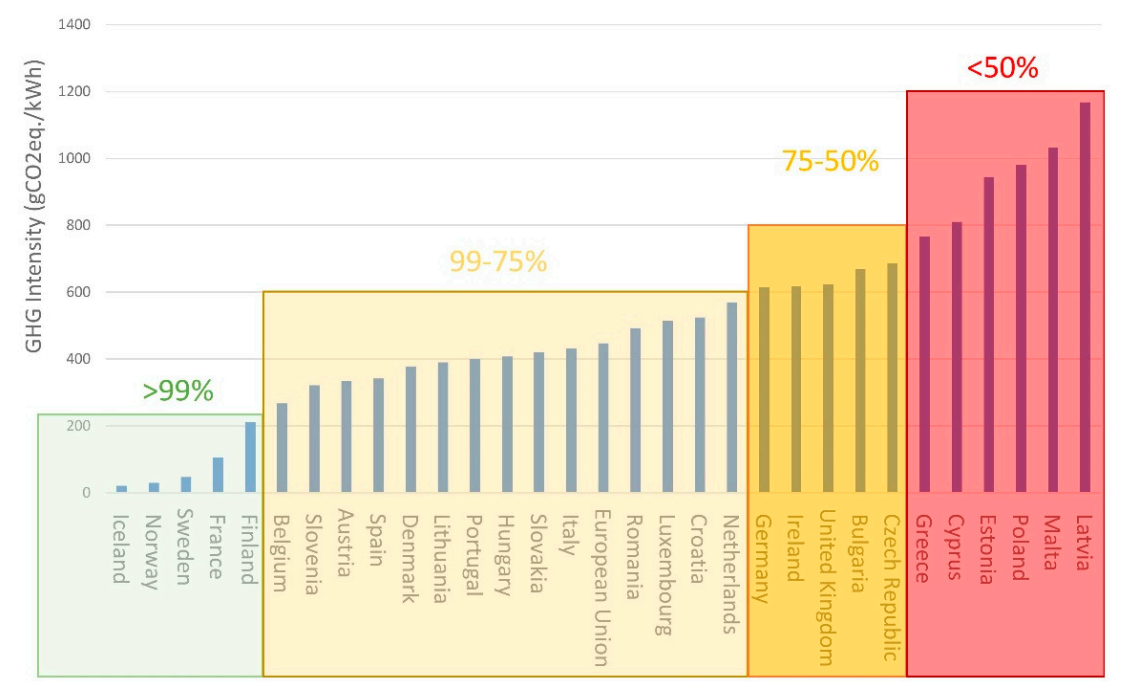

Figure 11. Groupings of probabilities that an EV will lead to lower life-cycle GHG emissions than a diesel vehicle.

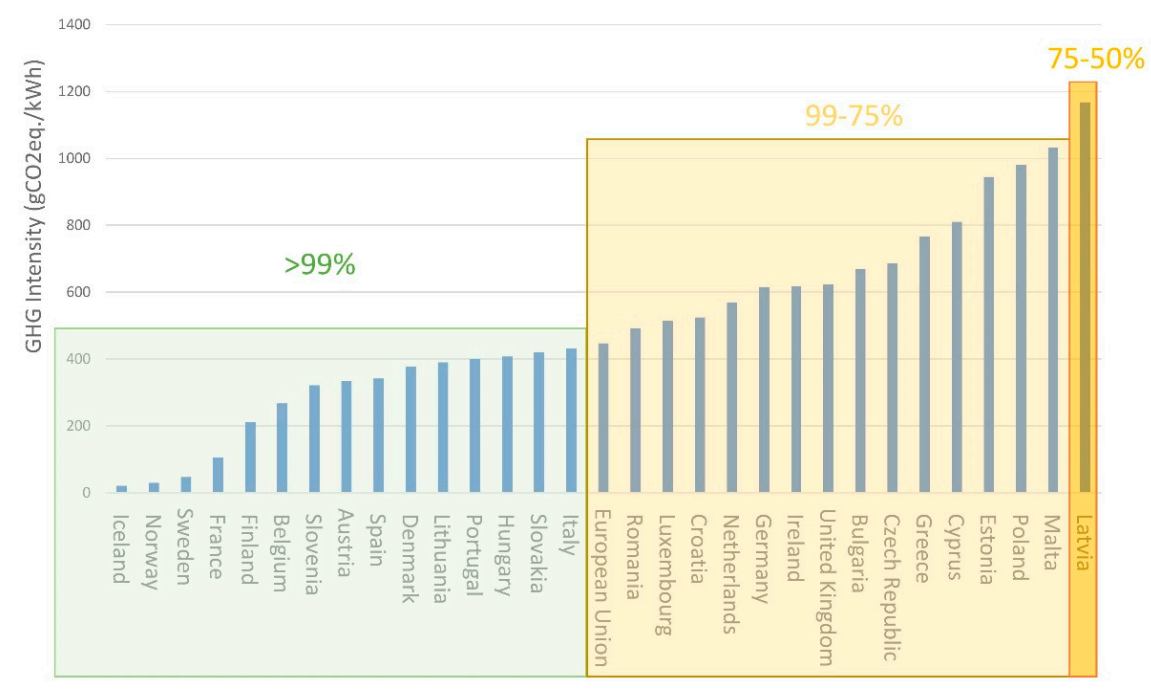

Figure 12. Groupings of probabilities that an EV will lead to lower life-cycle GHG emissions than a petrol vehicle. 


\section{Discussion and Conclusions}

\subsection{Discussion on the Review}

The review performed during this study aimed at understanding how existing and published LCA studies comparing EVs and ICEVs differ and how the field of study has developed as EV technologies have matured. Overall, the results of this review were consistent with those of previous LCA reviews, which emphasize the importance of the electricity source powering the EVs' use phase [9] and the necessity of inclusion and consideration of all life-cycle phases and datapoints suggested in this review and other frameworks $[5,8]$. This study additionally acknowledges the need for data transparency and clarity within studies to allow for cross-study comparability, particularly for key data points, such as battery capacity, fuel/energy efficiency, vehicle weight, and lifetime. Full data disclosure in the form of LCIs or other pre-analysis primary data would allow for enhanced reproducibility. This improvement of consistency across studies could improve future meta-analysis studies' efficacy and conclusiveness [7].

While performing the review, it was found that a variable amount of temporal learning across studies seemed to occur. While the inclusion of key data points seemed to improve over time, this learning did not extend to clear disclosure of the methodologies used within the studies (highlighted in this review, particularly for EOL, maintenance, and battery replacement). This lack of methodological transparency appeared to be uncorrelated with the time of publication. This lack of temporal improvement also applied to the disclosure of data in the form of full LCIs, where it did not appear that data have become more accessible over time, even with Hawkins et al. [8] review in place.

Therefore, this study's authors suggest higher data and methodological transparency, and at a minimum, studies should provide LCIAs disaggregated by the life-cycle phase within their results or as supplementary data, thus allowing future researchers the ability to analyze by life-cycle phase impacts. This echoes Brandão et al. [7] conclusions, highlighting the need for consistent methodologies and guidelines. Data quality is often a key factor when performing LCA studies for a specific technology to produce more consistent, comparable, and conclusive results.

\subsection{Discussion on the Operationalization of the Extracted Meta-Data}

RQ2 was formulated as: "How do the GHG intensities of the electrical grids across Europe affect EVs' environmental effectiveness?" Due to the contextual importance of the assumed electricity source within LCA studies, our use of meta-data for all life-cycle phases of EVs except the energy use phase aimed to reduce this variability through the use of a standardized methodology provided by Moro and Lonza [10]. Their results show relative consistency compared to other studies, though the inclusion of trading makes by-country cross-study comparisons difficult due to different the trading patterns over time [36,44]. This standardization attempts to address the gap presented by Marmiroli et al. [9], and was suggested by Zumsteg et al. [14].

The results in Section 3.2 highlight how important electrical grid and production emissions are for determining GHG emissions. They also emphasize the value of reproducibility, comparability, and accuracy for future studies' accuracy and policy relevance.

As the DIP and ED analyses showed, the contextual GHG emission intensity plays a significant role in determining EVs' efficacy in acting as a GHG mitigation solution. The DIPs showed that for countries with high electrical grid intensities, such as Poland, Estonia, Latvia, and Malta, EVs could potentially never reach an environmental breakeven point. Within the other countries, the DIPs showed highly varying breakeven points. For example, at an average annual driving distance between 10,000 and 15,000 km per year [45], it would take roughly 2-3.5 years and 7.5-11 years for an EV to break even against a diesel vehicle in the Icelandic and German contexts, respectively. These timelines decrease in petrol comparisons. The ED analysis illustrated this point further, showing that the by-country grid circumstance could lead to an estimated 35 tons $\mathrm{CO}_{2}$ equivalent difference in outcomes (Latvia vs. Iceland) in terms of the difference in life-cycle GHG emissions compared to a petrol or diesel vehicle. 
The MPE analysis displayed the importance of production emissions, illustrating how, in the diesel case, countries with the highest electrical grid GHG intensities (Poland, Malta, and Latvia) would need EVs to be produced with negative GHG emissions to be considered environmentally viable.

Conversely, in the petrol case, the MPE showed that in countries with the lowest electrical grid GHG intensities, it was estimated that EV production emissions could be three times and 4.5 times higher than for diesel and petrol cars, respectively, and act as environmentally viable mitigation solutions. Thus, the importance of grid GHG intensity highlights the need to consider the context within which EVs are being implemented, with a watchful eye towards the production emissions of both battery and chassis. Depending on the grid context, the maximum environmentally viable production emissions will change.

Reproducibility, comparability, and accuracy are essential for depicting the life-cycle GHG emissions associated with a vehicle. The MPE analysis highlighted this, where all countries encompassed in orange and red within Figure 11 had an MPE $<\left(\mu_{\mathrm{EV}}+\sigma_{\mathrm{EV}}\right)$ (mean plus one standard deviation from Table 7), and where if the emissions associated with producing an EV were incorrectly estimated, EVs could potentially lead to more GHG emissions over the life cycle of the vehicle than the comparative diesel vehicle. The Monte Carlo simulation further showed this, where uncertainty in whether EVs would outperform ICEVs spanned a broad range of GHG intensity values (500-1000 gCO $\mathrm{g}_{2} \mathrm{eq} / \mathrm{kWh}$ for diesel and even broader for EVs). While some of this uncertainty is undoubtedly due to the inherent variability found within an LCA meta-analysis (to be discussed further in the Section 4.3), this breadth displays the need for greater consistency between studies to gain greater confidence within the results. To make such results more conclusive and to accurately depict at what GHG grid intensity EVs should be implemented as a GHG mitigation solution, greater reproducibility, comparability, and accuracy will be needed within the field. The significance of most accurately portraying the environmental impact of EVs holds because if the science fails to do so, it could lead to the possibility of implementing GHG mitigation solutions to reduce GHG emissions only to increase them.

\subsection{Limitations and Further Study}

This study's most obvious limitation is inherent to a meta-analysis performed upon a complex product, such as a vehicle (EV or ICEV). Even with filtering through the selection criteria, variation existed within this criterion. Each vehicle is subject to the complex global supply chains organized by each major vehicle manufacturer, with models often changing annually. This variance extends to the samples studied within the review and could lead to potential bias within the results. For example, petrol and diesel vehicle comparisons were not included in every study, with diesel comparisons having a small diesel sample size $(n=6)$. Suppose that those six studies focused on smaller, more efficient diesel vehicles and smaller EV comparisons; in that case, this small sample size could potentially skew the results in one direction or the other.

While it can be argued that this variance and the variance discussed in the review seemingly make the results from the meta-analysis unreliable, it can conversely be argued that the review provides context to the meta-analysis so that it can be correctly understood and interpreted. As opposed to suggesting that each DIP, ED, and MPE are the exact values in which these different environmental breakevens would occur for every EV, the meta-analysis is an attempt to synthesize findings and provide insight into the average case across the field of EV/ICEV LCA comparison studies according to this study's selection criteria. It may more accurately reflect the performance of a region's mid-size EV/ICEV fleet's average life-cycle GHG emissions instead of a comparison of specific vehicle makes and models.

By understanding the variability provided by the review, the goal was thus to attempt to derive decision and policy support and considerations with the recognition of this variability [7]. This form of analysis has been performed across other technologies, such as electricity generation, biobased materials, desktop computers, consumer printers, and reviews. These can help develop more standardized LCA procedures within future studies [46-49]. Recommendations can also be made for further study areas, 
such as a greater number of diesel comparisons and performing cross-database comparative LCAs to understand the role of database selection further.

The variance discussed is further enhanced by the fact that EV production is still a maturing technology. The International Council on Clean Transportation (ICCT) presented potential developments that could impact the production emissions associated with battery packs and expected life-cycle impacts, namely: larger EV batteries $(+18 \%)$, battery second life $(-22 \%)$, battery recycling $(-4 \%)$, projected grid decarbonization $(-27 \%)$, and greater battery energy density $(-6 \%)$ [40]. These assumptions, however, are just for the battery pack. The production of both EVs' and ICEVs' chassis could benefit from projected grid decarbonization and are subject to the location in which the production occurs. The complicated supply chain associated with batteries and vehicles makes projecting future production emissions difficult. It seems likely, however, that as learning occurs and technology both for electricity generation and manufacturing develops, the production emissions of EV technologies should decrease. As more vehicle LCA data become available, projections regarding the changing environmental impact of EV production can be further improved.

This temporal limitation extends to the electricity mixes used within this analysis, as they remain constant. However, within a potential 10-20 year lifespan of a vehicle, the GHG emission intensity of national electricity grids will likely continue to decrease as more substantial political pressure is placed to address climate change [50]. This implies that the linear trajectories of the use-phase emissions illustrated in Figure 2 are likely to slowly curve downward over time as electrical grids are decarbonized [51]. This temporal aspect also applies to ICEVs, which are becoming increasingly efficient as technology improves, with the possibility of increased efficiency and use of biofuels. Despite this simplification, this study's results remain valuable, as they show a wide range of countries under different grid emission intensity conditions and, therefore, provide points of comparison for any country for the impact of different paces of improvement. Future studies could address these temporal limitations by adding a temporal component to the metrics provided in Sections 2.2.1-2.2.3. Based on planned electricity grid decarbonization pathways published by different countries, they could potentially use them for mapping when and at what decarbonization rates EVs would become environmentally viable.

There is also an additional uncertainty aspect that comes with average grid emissions, where the marginal emissions might vary significantly. An overview of how marginal emissions can be accounted for in the EV context has been performed, using the US as an example [52]. However, this is just one methodology, and to determine at which moment the marginal should be used and what the marginal is has multiple solutions, and is a complex task [53]. As such, its importance is acknowledged, but is considered out of the scope of this study.

As a final consideration, the entire discussion within this study revolves around EVs' potential to act as a replacement for ICEVs to achieve GHG reductions. However, lacking in such a discussion regarding GHGs and personal transport, outside of the transition to e-mobility, are the concepts and roles of travel demand and vehicle ownership [54,55]. There has been a field of studies discussing the role of e-mobility and its limitations. In terms of rapid transport-sector emission-reduction pathways (along with other factors, such as urban livability, available resources, air pollution, etc.), the current global level of vehicle ownership could already be considered unsustainable [56]. Particularly concerning the high production emissions associated with EVs as discussed throughout this study, a full one-to-one transition of global vehicle fleets from ICEVs to EVs would likely not achieve the deeper levels of decarbonization required to keep global warming below $1.5^{\circ} \mathrm{C}$ without addressing travel demand and vehicle ownership rates [57].

\subsection{Policy Implications}

EVs can eliminate TTW emissions and potentially reduce the WTW emissions associated with each country's transportation sector. However, for countries interested in promoting EVs as a GHG mitigation solution within their respective boundaries to meet their nationally determined contributions 
(NDCs), they should consider the vehicle's entire life cycle. Just because the emissions associated with producing a vehicle do not fall within a specific country's geographic boundary does not mean that they should not be considered when implementing national policies. GHG emissions are a global issue, and climate change impacts do not take human-drawn boundaries into account. Implementing policies that can lead to higher GHG emissions for a comparable life cycle to meet national goals while neglecting global goals could be detrimental to the purpose of the Paris Agreement.

The analysis displayed in this study can help EEA policymakers understand the role that EVs can play in climate mitigation strategy, taking local contexts into account. In countries with high electrical grid GHG intensities, such as Estonia or Poland, where the probability of EVs outperforming BEVs from a climate change perspective is low, the electricity production sector's decarbonization should likely be prioritized over car fleet electrification. The basic premises of the Polish and Estonian electromobility and energy plans are to increase the supply and demand for electric vehicles, thus increasing energy use. Poland has put in place policies promoting EVs by giving fiscal incentives, such as with a program that will provide up to about 4000 EUR for citizens to purchase EVs until the 8,300,000 EUR budget expires [58]; Estonia gives 5000 EUR per EV, with a budget of 600,000 EUR (with a likely larger allocation forthcoming) [59]. Simultaneously, the plans for decarbonizing energy production are relatively modest, with Poland assuming a gradual decrease from a $78 \%$ share of coal and lignite in 2017 to $56-60 \%$ in 2030 [60], and Estonia only seeks to increase its renewable energy share from $17 \%$ in 2020 to $30 \%$ in 2030 [61]. The soundness of these policies is contrasted when compared to those of Finland, a country where EVs would bring about considerable emission reductions, and where grants of 2000 EUR are provided for up 6,000,000 EUR annually for the purchasing of EVs, accompanied by an emissions-based taxation system for all vehicles (further subsidizing EVs) [62]. Finland, Poland, and Estonia have thus established similar policies regarding intention and scale, with vastly different electricity grid emission intensities (where Finland had a $41 \%$ share of renewable electricity in 2020, with a goal to reach $53 \%$ by 2030) [63]. This type of comparison can be made again between Iceland and Malta, two island nations with significantly differing GHG electrical grid intensities, and yet both have policies in place to remove registration and ownership taxes, purchase subsidies in the form of direct subsidies or VAT exemption, and incentives and grants for EV charging infrastructure [64]. With Malta's National Energy and Climate Plan goal to only increase the share of renewable electricity from $10 \%$ to $11 \%$ from 2020 to 2030, the similar EV policies of these two island nations contrast heavily in terms of achieved GHG outcomes.

These matching policies in different contextual circumstances give the appearance of policies being enacted without considering the global effects. When considering funding and policy allocations, policymakers should make efforts to prioritize either EVs or decarbonizing the electrical grid, or both at the same time, in line with local conditions that determine the effectiveness of the policies considered. Additionally, countries, consumers, and vehicle manufacturers need to push for further Environmental Product Declarations or similar assessments on vehicles and their components so that this knowledge can be more broadly shared and verified.

Applying the life-cycle thinking presented within this paper also places responsibility onto researchers. Suppose that the GHG emissions associated with producing EVs are underestimated or overestimated within the field of research; in that case, policymakers could potentially be misguided to promote or not promote environmental policies encouraging the uptake of EVs in line with the Paris Agreement and EU directives, with the possibility, in some cases, of actually increasing global life-cycle GHG emissions, countering the purpose of these national policies $[1,50]$. This added responsibility extends to vehicle and vehicle component manufacturers, who should closely monitor production emissions and promote environmental data transparency while attempting to meet the market's constant demand for longer range and larger battery capacity.

In conclusion, a need for greater methodological and data transparency within EV LCA research has been identified. Additionally, national and local policymakers should consider local context and life-cycle emissions when developing policies. Researchers need to do their part to perform LCAs 
with as much transparency and accuracy as possible to avoid the possibility of implementing GHG solutions that could unintentionally move us further away from humanity's ability to limit global warming to less than $1.5^{\circ} \mathrm{C}$.

Author Contributions: Conceptualization of the article was performed by K.J.D. and J.H. The methodology was developed by K.J.D. and J.H. Validations were performed by B.D. The formal analysis was performed by K.J.D. The investigation, resources, and data curation were performed by K.J.D. and Á.Á. All writing and reviews were performed by K.J.D. with edits from J.H., B.D., M.C., and Á.Á. All visualizations were developed by K.J.D. Supervision of the project was performed by J.H. Project Administration and funding acquisition were provided by J.H. and B.D. All authors have read and agreed to the published version of the manuscript.

Funding: This work was supported by the Icelandic research council (RANNIS) [grant numbers 185497-051, 2019].

Acknowledgments: The authors would additionally like to acknowledge Orkuveita Reykjavikur (Reykjavik Energy) for supporting this project.

Conflicts of Interest: The authors declare no conflict of interest.

\section{Appendix A}

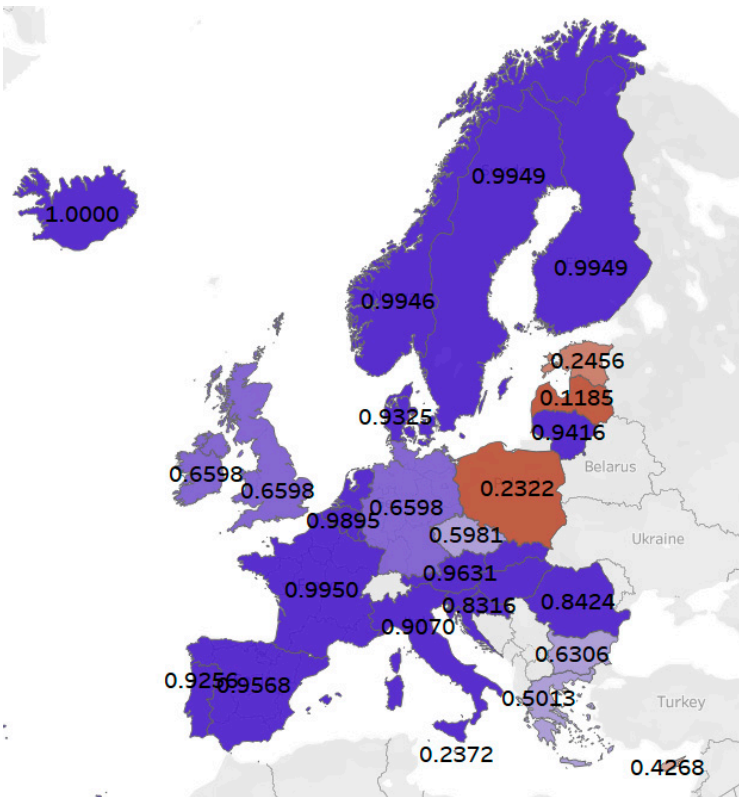

(a) Probability that an EV will lead to fewer lifecycle GHG emissions than the comparative diesel vehicle

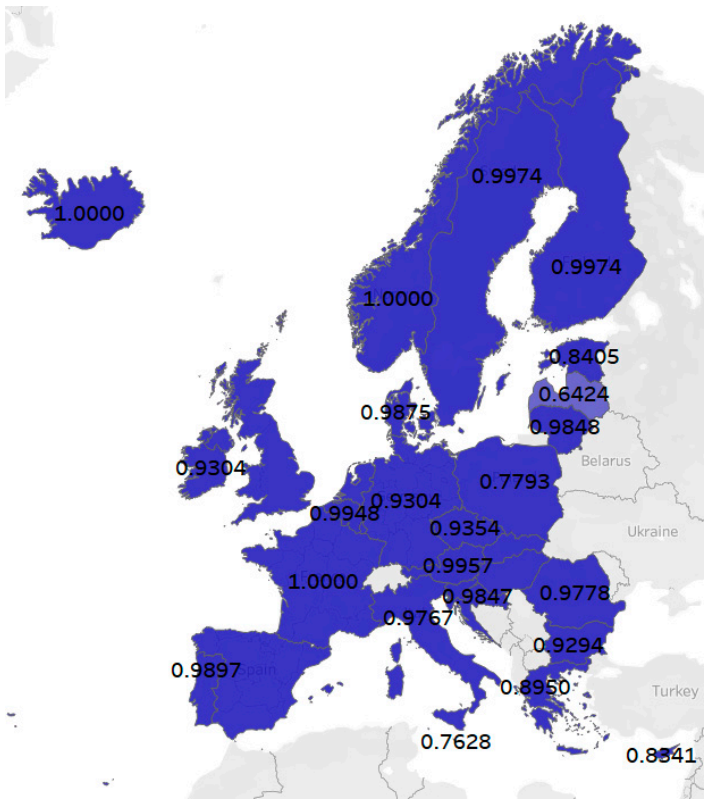

(b) Probability that EV will lead to fewer lifecycle GHG emissions than a comparative petrol vehicle

Figure A1. Probability that an EV would lead to less GHG emissions than a comparative (a) diesel or (b) petrol vehicle. 
Table A1. The data on each case considered within each study used within the review with included factors listed by year of publication.

\begin{tabular}{|c|c|c|c|c|c|c|c|}
\hline Study and Year & Vehicle Type & Lifetime (km) & $\begin{array}{l}\text { Battery Capacity } \\
\text { (kWh) }\end{array}$ & Country of Study & $\begin{array}{l}\text { EV Fuel Efficiency } \\
(\mathrm{kWh} / 100 \mathrm{~km})\end{array}$ & $\begin{array}{l}\text { ICEV Fuel Efficiency } \\
(\mathrm{l} / 100 \mathrm{~km})\end{array}$ & Total $\left(\mathrm{g} \mathrm{CO}_{2} / \mathrm{km}\right)$ \\
\hline Gao, L., and Winfield, Z. C. (2012) & Petrol & 256,000 & & US. & & 6.821235 & 265 \\
\hline Gao, L., and Winfield, Z. C. (2012) & BEV & 256,000 & 24 & US. & 21.15178 & & 231 \\
\hline Ma, Hongrui, et al. (2012) & Petrol & 180,000 & & UK. & & 6.4 & 201.2 \\
\hline Ma, Hongrui, et al. (2012) & Petrol & 289,500 & & US. & & 12.9 & 282.9 \\
\hline Ma, Hongrui, et al. (2012) & BEV & 180,000 & 35 & UK. & 14 & & 109.2 \\
\hline Ma, Hongrui, et al. (2012) & BEV & 289,500 & 35 & US. & no data & & 130.6 \\
\hline Sharma, R., et al. (2013) & Diesel & 150,000 & & Australia & & 4.5 & 173.4 \\
\hline Sharma, R., et al. (2013) & BEV & 150,000 & 19.2 & Australia & 12 & & 208.3 \\
\hline Sharma, R., et al. (2013) & Petrol & 150,000 & & Australia & & 12.5 & 410 \\
\hline Szczechowicz, E., Dederichs, T., and Schnettler, A. (2012) & Petrol & 150,000 & & Germany & & 7.5 & 252.7 \\
\hline Szczechowicz, E., Dederichs, T., and Schnettler, A. (2012) & $\mathrm{BEV}$ & 150,000 & 34.3 & Germany & 17.15 & & 163.9 \\
\hline Bartolozzi, I., Rizzi, F., and Frey, M. (2013) & BEV & $\begin{array}{l}\text { no lifetime given, only } \\
\text { emissions per km }\end{array}$ & 34.2 & Italy & 17 & & 110.35 \\
\hline Bartolozzi, I., Rizzi, F., and Frey, M. (2013) & BEV & $\begin{array}{l}\text { no lifetime given, only } \\
\text { emissions per km }\end{array}$ & 34.2 & Italy & 17 & & 121.2 \\
\hline Bartolozzi, I., Rizzi, F., and Frey, M. (2013) & BEV & $\begin{array}{l}\text { no lifetime given, only } \\
\text { emissions per km }\end{array}$ & 34.2 & Italy & 17 & & 178.25 \\
\hline Hawkins, Troy R., et al. (2013) & Diesel & 150,000 & & EU & & 6.85 & 228.439 \\
\hline Hawkins, Troy R., et al. (2013) & Petrol & 150,000 & & EU & & 5.35 & 259.732 \\
\hline Hawkins, Troy R., et al. (2013) & BEV & 150,000 & 24 & EU & 17.31 & & 194.017 \\
\hline Hawkins, Troy R., et al. (2013) & BEV & 150,000 & 24 & EU & 17.31 & & 225.31 \\
\hline Hawkins, Troy R., et al. (2013) & BEV & 150,000 & 24 & EU & 17.31 & & 309.801 \\
\hline Hawkins, Troy R., et al. (2013) & BEV & 150,000 & 24 & EU & 17.31 & & 206.534 \\
\hline Chatzikomis, C. I., Spentzas, K. N., and Mamalis, A. G. (2014) & Petrol & 150,000 & & Greece & & 7.13 & 228.9 \\
\hline Chatzikomis, C. I., Spentzas, K. N., and Mamalis, A. G. (2014) & BEV & 150,000 & 30 & Greece & 21 & & 198.7 \\
\hline Messagie et al. (2014) & Diesel & 230,500 & no data & EU & & 5.3 & 189 \\
\hline Messagie et al. (2014) & Diesel & 230,500 & no data & EU & & 5.9 & 195 \\
\hline Messagie et al. (2014) & Petrol & 230,500 & no data & EU & & 7.2 & 267 \\
\hline Messagie et al. (2014) & Petrol & 230,500 & no data & EU & & 7.1 & 270 \\
\hline Messagie et al. (2014) & Petrol & 230,500 & no data & $\mathrm{EU}$ & & 13.1 & 288 \\
\hline Messagie et al. (2014) & BEV & 230,500 & no data & $\mathrm{EU}$ & 17 & & 95 \\
\hline Bauer, Christian, et al. (2015) & Petrol & 240,000 & & EU & & no data & 301.33 \\
\hline Bauer, Christian, et al. (2015) & Diesel & 240,000 & & EU & & no data & 253.48 \\
\hline Bauer, Christian, et al. (2015) & BEV & 240,000 & 25 & $\mathrm{EU}$ & no data & & 66.86 \\
\hline Bauer, Christian, et al. (2015) & BEV & 240,000 & 25 & $\mathrm{EU}$ & no data & & 67.94 \\
\hline Bauer, Christian, et al. (2015) & BEV & 240,000 & 25 & $\mathrm{EU}$ & no data & & 70.36 \\
\hline Bauer, Christian, et al. (2015) & BEV & 240,000 & 25 & EU & no data & & 87.14 \\
\hline Bauer, Christian, et al. (2015) & BEV & 240,000 & 25 & $\mathrm{EU}$ & no data & & 185.94 \\
\hline Bauer, Christian, et al. (2015) & BEV & 240,000 & 25 & $\mathrm{EU}$ & no data & & 213.94 \\
\hline Bauer, Christian, et al. (2015) & BEV & 240,000 & 25 & $\mathrm{EU}$ & no data & & 370.94 \\
\hline
\end{tabular}


Table A1. Cont.

\begin{tabular}{|c|c|c|c|c|c|c|c|}
\hline Study and Year & Vehicle Type & Lifetime (km) & $\begin{array}{c}\text { Battery Capacity } \\
\text { (kWh) }\end{array}$ & Country of Study & $\begin{array}{l}\text { EV Fuel Efficiency } \\
\text { (kWh/100 km) }\end{array}$ & $\begin{array}{l}\text { ICEV Fuel Efficiency } \\
(\mathbf{l} / 100 \mathrm{~km})\end{array}$ & Total $\left(\mathrm{g} \mathrm{CO}_{2} / \mathrm{km}\right)$ \\
\hline Girardi, P., Gargiulo, A., and Brambilla, P. C. (2015) & Petrol & 150,000 & & Italy & & 6.83 & 308.0599 \\
\hline Girardi, P., Gargiulo, A., and Brambilla, P. C. (2015) & BEV & 150,000 & 24 & Italy & 19 & & 155.0967 \\
\hline Onat et al. (2015) & Petrol & 240,000 & & US. & & 7.6 & 263.4052 \\
\hline Onat et al. (2015) & BEV & 240,000 & 24 & US. & no data & & 195.22 \\
\hline Tagliaferri at al. (2016) & $\mathrm{BEV}$ & 150,000 & 24 & $\mathrm{EU}$ & 15.56 & & 117.7 \\
\hline Tagliaferri at al. (2016) & Diesel & 150,000 & 24 & $\mathrm{EU}$ & & 5 & 170 \\
\hline Burchart-Korol, Dorota, et al. (2018) & $\mathrm{BEV}$ & 150,000 & 29.9 & Czech Republic & 19.9 & & 220.38 \\
\hline Burchart-Korol, Dorota, et al. (2018) & BEV & 150,000 & 29.9 & Poland & 19.9 & & 282.71 \\
\hline Gawron, James H., et al. (2018) & Petrol & 257,495 & & US. & & & 266.5721 \\
\hline Gawron, James H., et al. (2018) & BEV & 257,495 & 23 & US. & 19.57 & & 138.725 \\
\hline Gawron, James H., et al. (2018) & $\mathrm{BEV}$ & 257,495 & 23 & US. & 19.57 & & 153.0942 \\
\hline Wu et al. (2018) & Petrol & 150,000 & no data & China & & 8.3 & 233.73 \\
\hline Wu et al. (2018) & Petrol & 150,000 & no data & China & & 8.9 & 268.27 \\
\hline Wu et al. (2018) & $\mathrm{BEV}$ & 150,000 & no data & China & 19.4 & & 218.8 \\
\hline Wu et al. (2018) & BEV & 150,000 & no data & China & 23.8 & & 288.4 \\
\hline Bekel, K., and Pauliuk, S. (2019) & Petrol & 150,000 & & Germany & & no data & 326.4 \\
\hline Bekel, K., and Pauliuk, S. (2019) & BEV & 150,000 & 35.8 & Germany & 17.53 & & 139.7 \\
\hline Kawamoto et al. (2019) & Petrol & 200,000 & & $\mathrm{EU}$ & & 5.102041 & 170.33 \\
\hline Kawamoto et al. (2019) & Petrol & 200,000 & & Australia & & 5.813953 & 182.83 \\
\hline Kawamoto et al. (2019) & Petrol & 200,000 & & China & & 6.21118 & 195.33 \\
\hline Kawamoto et al. (2019) & Petrol & 200,000 & & US. & & 7.575758 & 245.33 \\
\hline Kawamoto et al. (2019) & Diesel & 200,000 & & EU & & 3.802281 & 140.33 \\
\hline Kawamoto et al. (2019) & Diesel & 200,000 & & Japan & & 4.62963 & 170.33 \\
\hline Kawamoto et al. (2019) & BEV & 200,000 & 35.8 & $\mathrm{EU}$ & 12.70648 & & 146.57 \\
\hline Kawamoto et al. (2019) & BEV & 200,000 & 35.8 & Japan & 12.40695 & & 171.57 \\
\hline Kawamoto et al. (2019) & BEV & 200,000 & 35.8 & U.S. & 17.3913 & & 202.01 \\
\hline Kawamoto et al. (2019) & BEV & 200,000 & 35.8 & China & 12.70648 & & 204.9 \\
\hline Kawamoto et al. (2019) & BEV & 200,000 & 35.8 & Australia & 12.70648 & & 213.23 \\
\hline Li, Y., Ha, N., and Li, T. (2019) & Petrol & 260,000 & & China & & & 359.6 \\
\hline Li, Y., Ha, N., and Li, T. (2019) & Petrol & 260,000 & & China & & & 386.9 \\
\hline Li, Y., Ha, N., and Li, T. (2019) & Petrol & 260,000 & & China & & & 418.1 \\
\hline Li, Y., Ha, N., and Li, T. (2019) & BEV & 260,000 & 17.7 & China & 11.67 & & 456.7 \\
\hline Li, Y., Ha, N., and Li, T. (2019) & Petrol & 260,000 & & China & & & 437.7 \\
\hline Li, Y., Ha, N., and Li, T. (2019) & $\mathrm{BEV}$ & 260,000 & 24.4 & China & 13.71 & & 487.8 \\
\hline Li, Y., Ha, N., and Li, T. (2019) & BEV & 260,000 & 42.1 & China & 14.98 & & 518.9 \\
\hline Li, Y., Ha, N., and Li, T. (2019) & BEV & 260,000 & 59.9 & China & 16.77 & & 565.9 \\
\hline Xiong, S., Ji, J., and Ma, X. (2019) & BEV & 160,000 & 47.5 & China & 15.3 & & 201.93 \\
\hline Xiong, S., Ji, J., and Ma, X. (2019) & BEV & 120,000 & 60.5 & China & 15.2 & & 237.57 \\
\hline
\end{tabular}




\section{References}

1. European Commission. A European Strategy for Low-Emission Mobility. In Communication from the Commission to the European Parliament, the Council, the European Economic and Social Committeee and the Committee of the Regions; European Commission: Brussels, Belgium, 2016.

2. IPCC. Transport. In Climate Change: Mitigation of Climate Change: Contribution of Working Group III to the Fifth Assessment Report of the IPCC; Intergovernmental Panel on Climate Change, Cambridge University Press: Cambridge, UK, 2014.

3. Woo, J.; Choi, H.; Ahn, J. Well-to-wheel analysis of greenhouse gas emissions for electric vehicles based on electricity generation mix: A global perspective. Transp. Res. Part D Transp. Environ. 2017, 51, 340-350. [CrossRef]

4. International Organization for Standardizaiton (ISO). Environmental Management-Life Cycle AssessmentPrinciples and Framework; ISO 14040:2006; ISO: Geneva, Switzerland, 2006.

5. Egede, P.; Dettmer, T.; Herrmann, C.; Kara, S. Life Cycle Assessment of Electric Vehicles-A Framework to Consider Influencing Factors. Procedia CIRP 2015, 29, 233-238. [CrossRef]

6. Nordelöf, A.; Messagie, M.; Tillman, A.M.; Söderman, M.L.; Van Mierlo, J. Environmental impacts of hybrid, plug-in hybrid, and battery. Int. J. Life Cycle Assess. 2014, 19, 1866-1890. [CrossRef]

7. Brandao, M.; Heath, G.; Cooper, J. What Can Meta-Analyses Tell Us About the Reliability of Life Cycle Assessment for Decision Support? J. Ind. Ecol. 2012, 16, S3-S7. [CrossRef]

8. Hawkins, T.R.; Gausen, O.M.; Strømman, A.H. Environmental impacts of hybrid and electric vehicles-A review. Int. J. Life Cycle Assess. 2012, 17, 997-1014. [CrossRef]

9. Marmiroli, B.; Messagie, M.; Dotelli, G.; Van Mierlo, J. Electricity Generation in LCA of Electric Vehicles: A Review. Appl. Sci. 2018, 8, 1384. [CrossRef]

10. Moro, A.; Lonza, L. Electricity carbon intensity in European Member States: Impacts on GHG emissions of electric vehicles. Transp. Res. Part D Transp. Environ. 2018, 64, 5-14. [CrossRef]

11. Ellingsen, L.A.W.; Singh, B.; Strømman, A.H. The size and range effect: Lifecycle greenhouse gas emissions of electric vehicles. Environ. Res. Lett. 2016, 11, 054010. [CrossRef]

12. Zamagni, A.; Masoni, P.; Buttol, P.; Raggi, A.; Buonamici, R. Finding Life Cycle Assessment Research Direction with the Aid of Meta-Analysis. J. Ind. Ecol. 2012, 16, S39-S52. [CrossRef]

13. Kawamoto, R.; Mochizuki, H.; Moriguchi, Y.; Nakano, T.; Motohashi, M.; Sakai, Y.; Inaba, A. Estimation of $\mathrm{CO}_{2}$ Emissions of Internal Combustion Engine Vehicle and Battery Electric Vehicle Using LCA. Sustainability 2019, 11, 2690. [CrossRef]

14. Zumsteg, J.M.; Cooper, J.S.; Noon, M.S. Systematic Review Checklist: A Standardized Technique for Assessing and Reporting Reviews of Life Cycle Assessment Data. J. Ind. Ecol. 2012, 16, S12-S21. [CrossRef]

15. Moher, D.; Liberati, A.; Tetzlaff, J.; Altman, D.G.; The PRISMA Group. Preferred Reporting Items for Systematic Reviews and Meta-Analyses: The PRISMA Statement. PLoS Med. 2009, 6, e1000097. [CrossRef]

16. Hawkins, T.R.; Singh, B.; Majeau-Bettez, G.; Strømman, A.H. Comparative Environmental Life Cycle Assessment of Conventional and Electric Vehicles. J. Ind. Ecol. 2013, 17, 53-64. [CrossRef]

17. Gao, L.; Winfield, Z.C. Life Cycle Assessment of Environmental and Economic Impacts of Advanced Vehicles. Energies 2012, 5, 605-620. [CrossRef]

18. Ma, H.; Balthasar, F.; Tait, N.; Riera-Palou, X.; Harrison, A. A new comparison between the life cycle greenhouse gas emissions of battery electric vehicles and internal combustion vehicles. Energy Policy 2012, 44, 160-173. [CrossRef]

19. Szczechowicz, E.; Dederichs, T.; Schnettler, A. Regional assessment of local emissions of electric vehicles using traffic simulations for a use case in Germany. Int. J. Life Cycle Assess. 2012, 17, 1131-1141. [CrossRef]

20. Bartolozzi, I.; Rizzi, F.; Frey, M. Comparison between hydrogen and electric vehicles by life cycle assessment: A case study in Tuscany, Italy. Appl. Energy 2013, 101, 103-111. [CrossRef]

21. Sharma, R.; Manzie, C.; Bessede, M.; Crawford, R.H.; Brear, M.J. Conventional, hybrid and electric vehicles for Australian driving conditions. Part 2: Life cycle $\mathrm{CO}_{2}$-e emissions. Transp. Res. Part C Emerg. Technol. 2013, 28, 63-73. [CrossRef]

22. Chatzikomis, C.I.; Spentzas, K.N.; Mamalis, A.G. Environmental and economic effects of widespread introduction of electric vehicles in Greece. Eur. Transp. Res. Rev. 2014, 6, 365-376. [CrossRef] 
23. Messagie, M.; Boureima, F.S.; Coosemans, T.; Macharis, C.; Mierlo, J.V. A Range-Based Vehicle Life Cycle Assessment Incorporating Variability in the Environmental Assessment of Different Vehicle Technologies and Fuels. Energies 2014, 7, 1467-1482. [CrossRef]

24. Bauer, C.; Hofer, J.; Althaus, H.J.; Del Duce, A.; Simons, A. The environmental performance of current and future passenger vehicles: Life cycle assessment based on a novel scenario analysis framework. Appl. Energy 2015, 157, 871-883. [CrossRef]

25. Girardi, P.; Gargiulo, A.; Brambilla, P.C. A comparative LCA of an electric vehicle and an internal combustion engine vehicle using the appropriate power mix: The Italian case study. Girardi, Pierpaolo, Gargiulo, Alessia and Brambilla, Paola Cristina. Int. J. Life Cycle Assess. 2015, 20, 1127-1142. [CrossRef]

26. Onat, N.C.; Kucukvar, M.; Tatari, O. Conventional, hybrid, plug-in hybrid or electric vehicles? State-based comparative carbon and energy footprint analysis in the United States. Appl. Energy 2015, 150, 36-49. [CrossRef]

27. Tagliaferri, C.; Evangelisti, S.; Acconcia, F.; Domenech, T.; Ekins, P.; Barletta, D.; Lettieri, P. Life cycle assessment of future electric and hybrid vehicles: A cradle-to-grave systems engineering approach. Chem. Eng. Res. Des. 2016, 112, 298-309. [CrossRef]

28. Burchart-Korol, D.; Jursova, S.; Folegga, P.; Korol, J.; Pustejovska, P.; Blaut, A. Environmental life cycle assessment of electric vehicles in Poland and the Czech Republic. J. Clean. Prod. 2018, 202, 476-487. [CrossRef]

29. Gawron, J.H.; Keoleian, G.A.; De Kleine, R.D.; Wallington, T.J.; Kim, H.C. Life cycle assessment of connected and automated vehicles: Sensing and computing subsystem and vehicle level effects. Environ. Sci. Technol. 2018, 52, 3249-3256. [CrossRef]

30. Wu, Z.; Wang, M.; Zheng, J.; Sun, X.; Zhao, M.; Wang, X. Life cycle greenhouse gas emission reduction potential of battery electric vehicle. J. Clean. Prod. 2018, 190, 462-470. [CrossRef]

31. Bekel, K.; Pauliuk, S. Prospective cost and environmental impact assessment of battery and fuel cell electric vehicles in Germany. Int. J. Life Cycle Assess. 2019, 24, 2220-2237. [CrossRef]

32. Li, Y.; Ha, N.; Li, T. Research on Carbon Emissions of Electric Vehicles throughout the Life Cycle Assessment Taking into Vehicle Weight and Grid Mix Composition. Energies 2019, 12, 3612. [CrossRef]

33. Xiong, S.; Ji, J.; Ma, X. Comparative Life Cycle Energy and GHG Emission Analysis for BEVs and PhEVs: A Case Study in China. Energies 2019, 12, 834. [CrossRef]

34. Crawford, R.H.; Bontinck, P.A.; Stephan, A.; Wiedmann, T.; Yu, M. Hybrid life cycle inventory methods-A review. J. Clean. Prod. 2018, 172, 1273-1288. [CrossRef]

35. Pomponi, F.; Lenzen, M. Hybrid life cycle assessment (LCA) will likely yield more accurate results than process-based LCA. J. Clean. Prod. 2018, 176, 210-215. [CrossRef]

36. Säynäjoki, A.; Heinonen, J.; Junnonen, J.M.; Junnila, S. Input-output and process LCAs in the building sector: Are the results compatible with each other? Carbon Manag. 2017, 8, 155-166. [CrossRef]

37. Lenzen, M. Errors in Conventional and Input-Output-Based Life-Cycle Inventories. J. Ind. Ecol. 2008, 4, 127-148. [CrossRef]

38. Romare, M.; Dahllöf, L. The Life Cycle Energy Consumption and Greenhouse Gas Emissions from Lithium-Ion Batteries; IVL Swedish Environmental Research Institute: Stockholm, Sweden, 2017; Volume 23.

39. Emami, N.; Heinonen, J.; Marteinsson, B.; Säynäjoki, A.; Junnonen, J.M.; Laine, J.; Junnila, S. A Life Cycle Assessment of Two Residential Buildings Using Two Different LCA Database-Software Combinations: Recognizing Uniformities and Inconsistencies. Buildings 2019, 9, 20. [CrossRef]

40. The International Council on Clean Transportation. Effects of Battery Manufacturing on Electric Vehicle Life-Cycle Greenhouse Gas Emissions; International Council Clean Transportation: Washington, DC, USA, 2018.

41. Pryshlakivsky, J.; Searcy, C. An uncertainty analysis of the energy intensity of 37 materials used in automobile manufacturing: Statistical methods and recommendations. Sustain. Prod. Consum. 2020, 24, 12-25. [CrossRef]

42. Skrúcaný, T.; Kendra, M.; Stopka, O.; Milojević, S.; Figlus, T.; Csiszár, C. Impact of the Electric Mobility Implementation on the Greenhouse Gases Production in Central European Countries. Sustainability 2019, 11,4948 .

43. Weidema, B.P.; Frees, N.; Nielsen, A.M. Marginal production technologies for life cycle inventories. Int. J. Life Cycle Assess. 1999, 4, 48-56. [CrossRef]

44. Tranberg, B.; Corradi, O.; Lajoie, B.; Gibon, T.; Staffell, I.; Andresen, G.B. Real-time carbon accounting method for the European electricity markets. Energy Strategy Rev. 2019, 26, 100367. [CrossRef]

45. Millard-Ball, A.; Schipper, L. Are We Reaching Peak Travel? Trends in Passenger Transport in Eight Industrialized Countries. Transp. Rev. 2011, 31, 357-378. [CrossRef] 
46. Burkhardt, J.J., III; Heath, G.; Cohen, E. Life cycle greenhouse gas emissions of trough and tower concentrating solar power electricity generation: Systematic review and harmonization. J. Ind. Ecol. 2012, 16, S93-S109. [CrossRef]

47. Weiss, M.; Haufe, J.; Carus, M.; Brandão, M.; Bringezu, S.; Hermann, B.; Patel, M.K. A review of the environmental impacts of biobased materials. J. Ind. Ecol. 2012, 16, S169-S181. [CrossRef]

48. Teehan, P.; Kandlikar, M. Sources of variation in life cycle assessments of desktop computers. J. Ind. Ecol. 2012, 16, S182-S194. [CrossRef]

49. Bousquin, J.; Gambeta, E.; Esterman, M.; Rothenberg, S. Life cycle assessment in the print industry: A Critical Review. J. Ind. Ecol. 2012, 16, S195-S205. [CrossRef]

50. United Nations. Transforming Our World: The 2030 Agenda for Sustainable Development; United Nations: Copenhagen, Denmark, 2015.

51. European Environment Agency. National emissions reported to the UNFCCC and to the EU Greenhouse Gas Monitoring Mechanism. Reykjavik: S.n., 6, 16. 2020. Available online: https: //www.eea.europa.eu/data-and-maps/data/national-emissions-reported-to-the-unfccc-and-to-the-eugreenhouse-gas-monitoring-mechanism-16 (accessed on 16 June 2020).

52. Zivin, J.S.G.; Kotchen, M.J.; Mansur, E.T. Spatial and temporal heterogeneity of marginal emissions: Implications for electric cars and other electricity-shifting policies. J. Econ. Behav. Organ. 2014, 107, 248-268. [CrossRef]

53. Heinonen, J.; Laine, J.; Pluuman, K.; Säynäjoki, E.S.; Soukka, R.; Junnila, S. Planning for a Low Carbon Future? Comparing Heat Pumps and Cogeneration as the Energy System Options for a New Residential Area. Energies 2015, 8, 9137-9154. [CrossRef]

54. Holden, E.; Banister, D.; Gössling, S.; Gilpin, G.; Linnerud, K. Grand Narratives for sustainable mobility: A conceptual review. Energy Res. Soc. Sci. 2019. [CrossRef]

55. Creutzig, F.; Roy, J.; Lamb, W.F.; Azevedo, I.M.; De Bruin, W.B.; Dalkmann, H.; Edelenbosch, O.Y.; Geels, F.W.; Grubler, A.; Hepburn, C.; et al. Towards demand-side solutions for mitigating climate change. Nat. Clim. Chang. 2018, 8, 260. [CrossRef]

56. García-Olivares, A.; Solé, J.; Osychenko, O. Transportation in a $100 \%$ renewable energy system. Energy Convers. Manag. 2018, 158, 266-285. [CrossRef]

57. García-Olivares, A. Substitutability of Electricity and Renewable Materials for Fossil Fuels in a Post-Carbon Economy. Energies 2015, 8, 13308-13343. [CrossRef]

58. Polish Ministry of Energy. Electromobility Development Plan in Poland: Energy for the Future. Polish Ministry of Energy, 2016. Available online: https://www.gov.pl/web/klimat/elektromobilnosc (accessed on 16 June 2020).

59. Keskkonnaministri Määruse. Täiselektriliste Sõidukite Ostutoetuse Andmise Tingimused ja Kord. 2020. Available online: https://www.riigiteataja.ee/akt/113122019018 (accessed on 30 October 2020).

60. Polish Ministry of Energy. National Energy and Climate Plan for the Years 2021-2030; Polish Ministry of Energy: Warsaw, Poland, 2019.

61. Ministerstwo Klimatu. Program "Zielony Samochód". Ministerstwo Klimatu, 2020. Available online: https://www.gov.pl/web/klimat/program-zielony-samochod (accessed on 16 June 2020).

62. European Alternative Fuels Observatory. Finland-Incentives and Legislation. European Alternative Fuels Observatory. 2020. Available online: https://www.eafo.eu/countries/finland/1732/incentives (accessed on 16 June 2020).

63. Ministry of Economic Affairs and Employment. Finland's Integrated Energy and Climate Plan; Ministry of Economic Affairs and Employment: Helsinki, Finland, 2019.

64. European Alternative Fuels Observatory. Malta-Incentives and Legislation. European Alternative Fuels Observatory. 2020. Available online: https://www.eafo.eu/countries/malta/1744/incentives (accessed on 16 June 2020).

Publisher's Note: MDPI stays neutral with regard to jurisdictional claims in published maps and institutional affiliations. 